\title{
Validation of the HIRHAM-Simulated Indian Summer Monsoon Circulation
}

\author{
Stefan Polanski, Annette Rinke, and Klaus Dethloff \\ Research Unit Potsdam, Alfred Wegener Institute for Polar and Marine Research, Telegrafenberg A43, 14473 Potsdam, Germany \\ Correspondence should be addressed to Stefan Polanski, stefan.polanski@awi.de \\ Received 9 June 2010; Revised 6 September 2010; Accepted 27 October 2010 \\ Academic Editor: Hann-Ming Henry Juang \\ Copyright () 2010 Stefan Polanski et al. This is an open access article distributed under the Creative Commons Attribution License, \\ which permits unrestricted use, distribution, and reproduction in any medium, provided the original work is properly cited.
}

The regional climate model HIRHAM has been applied over the Asian continent to simulate the Indian monsoon circulation under present-day conditions. The model is driven at the lateral and lower boundaries by European reanalysis (ERA40) data for the period from 1958 to 2001. Simulations with a horizontal resolution of $50 \mathrm{~km}$ are carried out to analyze the regional monsoon patterns. The focus in this paper is on the validation of the long-term summer monsoon climatology and its variability concerning circulation, temperature, and precipitation. Additionally, the monsoonal behavior in simulations for wet and dry years has been investigated and compared against several observational data sets. The results successfully reproduce the observations due to a realistic reproduction of topographic features. The simulated precipitation shows a better agreement with a high-resolution gridded precipitation data set over the central land areas of India and in the higher elevated Tibetan and Himalayan regions than ERA40.

\section{Introduction}

The Asian monsoon circulation is characterized by variability on seasonal, interannual, and interdecadal time scales and impacts on water availability in a highly populated region with dominating agriculture. For this reason, the understanding of the complex mechanisms and interactions between the atmospheric patterns affecting the entire monsoon system is of special interest. Global general circulation models (GCMs) are often used to simulate the largescale circulation of the monsoon (e.g., [1-3]). Regional Climate Model (RCM) systems with higher spatial and temporal resolutions can add value at regional scales to the climate statistics when driven by GCMs with accurate large scales. Therefore, RCMs nested in a GCM or driven by data analyses have been applied for a special area of interest by dynamical downscaling and to improve their performance (e.g., $[4,5])$. Several RCM simulations have been carried out for the South Asian Monsoon region (e.g., [6-13]).

In this study, we apply the regional climate model HIRHAM on an Asian integration domain and analyze a 44-year-long simulation 1958-2001 driven by ECMWF reanalysis (ERA40 data). The HIRHAM model is one state-of-the-art RCM and has been already successfully applied for European regions (e.g., [14, 15]), for the Arctic (e.g., $[16-18]$ ) as well as for Antarctica (e.g., $[19,20]$ ). HIRHAM has been integrated over the Asian continent covering the high topography of Himalayas and Tibetan Plateau to simulate the Indian monsoon under present-day conditions. Before the model can be applied to improve the understanding of the regional coupling between monsoon circulation and orographic as well as thermal processes in the Himalayas and Tibetan Plateau, an essential prerequisite is the careful validation of the model simulations. Therefore, in the present study, the model integration over 44 years has been validated against observational data. The focus is on the validation of the summer monsoon circulation and the comparison of regional atmospheric circulation, temperature, and precipitation patterns between the HIRHAM model and the observational data. Related to this, the long-term climatology, the variability, and the monsoon behavior in selected wet and dry monsoon years have been evaluated. After a short introduction of the HIRHAM model and the used observational data sets (Section 2), the simulation results for mean sea level pressure, $2 \mathrm{~m}$ air 


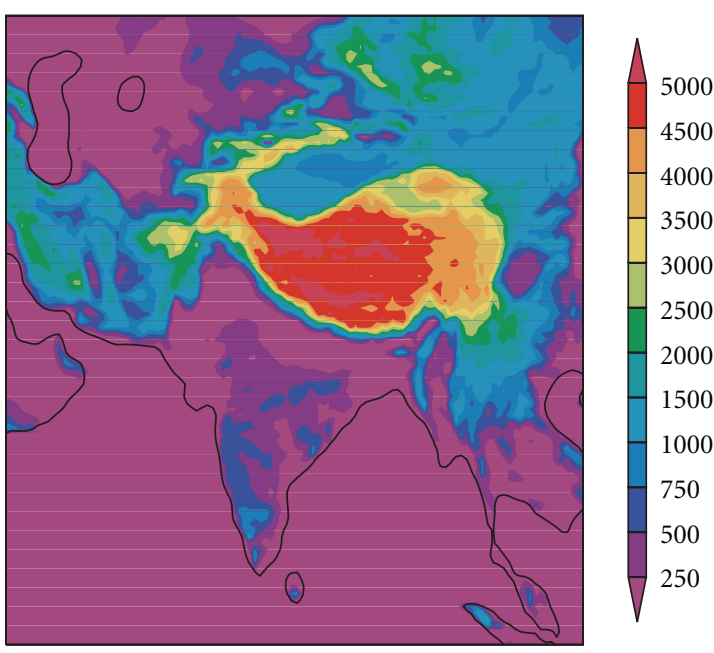

FIGURE 1: Integration domain and orography ( $\mathrm{m}$; shaded) of HIRHAM.

temperature and precipitation, geopotential and wind at different vertical levels, and a potential convective instability index are validated against the different data sets (Section 3 ). Finally, concluding remarks summarize the main results (Section 4).

\section{Model and Observational Data}

2.1. Regional Climate Model HIRHAM. The regional climate model HIRHAM used in this study has been developed by Christensen et al. [21]. It has been adapted to polar regions by Dethloff et al. [22] and Rinke et al. [23]. The dynamical part of the model is based on the hydrostatic limited-area model HIRLAM (High-Resolution Limited Area Model) [24] with prognostic equations for horizontal wind components, temperature, specific humidity, cloud water content, and surface pressure. The physical parameterizations for radiation, land surface processes, sea surface sea-ice processes, planetary boundary layer turbulence, gravity wave drag, cumulus convection, and large-scale condensation are taken from the general circulation model ECHAM4 [25]. Details of the model dynamics and physics can be found in the given references.

The integration domain in the Asian region (see Figure 1) covers an area between $0^{\circ} \mathrm{N}$ to $50^{\circ} \mathrm{N}$ and $42^{\circ} \mathrm{E}$ to $110^{\circ} \mathrm{E}$, including the high topography of the Tibetan Plateau and the Himalayas as well as the northern Indian Ocean. The model domain includes $110 \times 100$ grid points and a horizontal resolution of $0.5^{\circ}$. The vertical discretization consists of 19 irregularly spaced levels in hybrid $\sigma$-p coordinates from the surface up to $10 \mathrm{hPa}$. The model time step is $300 \mathrm{~s}$.

The model has been run over the ERA40 period, that is, for 44 years from 1958 to 2001. At the lateral and lower boundaries, HIRHAM has been forced by ERA40 reanalysis data from the spatially interpolated $0.5^{\circ}$ grid (see Section 2.2). The lateral forcing includes all prognostic variables except the cloud water content. The information from the lateral boundaries is transferred into the model interior by a boundary relaxation [26] in a 10-grid-pointwide boundary zone with boundary data updated 4 times a day. At the lower boundary, ECMWF-analyzed sea surface temperature has been used and updated daily.

2.2. Observational Data Sets. The model validation has been carried out by using gridded data from different sources, in which the data sets have been compared with the model output and with each other.

Table 1 contains all gridded data sets used for model validation. The data are characterized by a different spatial and temporal resolution. From the ERA40 reanalysis of the European Centre for Medium-Range Weather Forecasts (ECMWF) [27], the $2 \mathrm{~m}$ air temperature, mean sea level pressure, precipitation, geopotential, and wind have been used. From the Global Precipitation Climatology Centre, the GPCC4 data set for precipitation has been applied; (ftp://ftpanon.dwd.de/pub/data/gpcc/html/fulldata_download.html [28]). Additionally from the Indian Meteorological Department (IMD) [29], the precipitation data are analyzed.

2.3. Analysis Methods. In order to carry out direct comparisons between the gridded data sets and the model simulation results, the observations have been interpolated to the HIRHAM grid. For the quantitative comparison between HIRHAM and the gridded data, common statistical parameters (root mean square error (RMSE), bias "HIRHAM model minus observation" (BIAS), and pattern correlation coefficient (PATCOR)) have been calculated for the entire model area (ALL) as well as for subdomains with regionally specific criteria of selection (see Table 2: land surface (LAND), ocean (SEA), mountains with elevations higher than $1500 \mathrm{~m}$ a.s.l. (ELEV1500), and the Indian continent (INDIA)).

\section{Results}

The three-dimensional dynamical processes of the complex Indian monsoon circulation and its characteristic patterns (e.g., [30-32]) will be described in the following by an extensive validation of the model. The focus is on summer monsoon (June-September), 1958-2001.

3.1. Atmospheric Circulation. For the validation of the mean circulation patterns at different atmospheric levels, the seasonal mean ERA40 reanalysis data have been used. Figure 2 represents the mean sea level pressure and the 500$\mathrm{hPa}$ geopotential height, averaged over the simulation period 1958-2001 for the summer monsoon season (JJAS).

The HIRHAM simulation shows an extended low pressure system in northwestern India, which covers the entire northern part of India, the Indo-Gangetic plains south of the Himalayas and the northern Indian Ocean with values below $1000 \mathrm{hPa}$. It is connected to the position of the near-surface monsoonal heat depression. Most parts of the domain are characterized by small differences "HIRHAMERA40", ranging from $-2 \mathrm{hPa}$ to $+2 \mathrm{hPa}$ for mean sea 


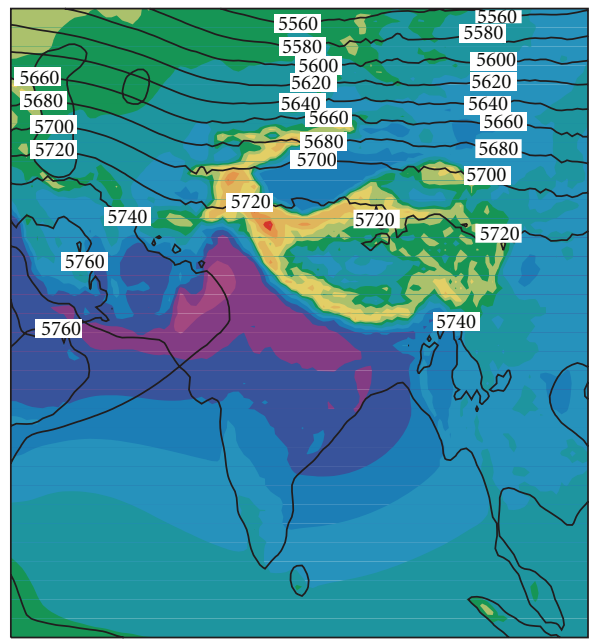

(a)
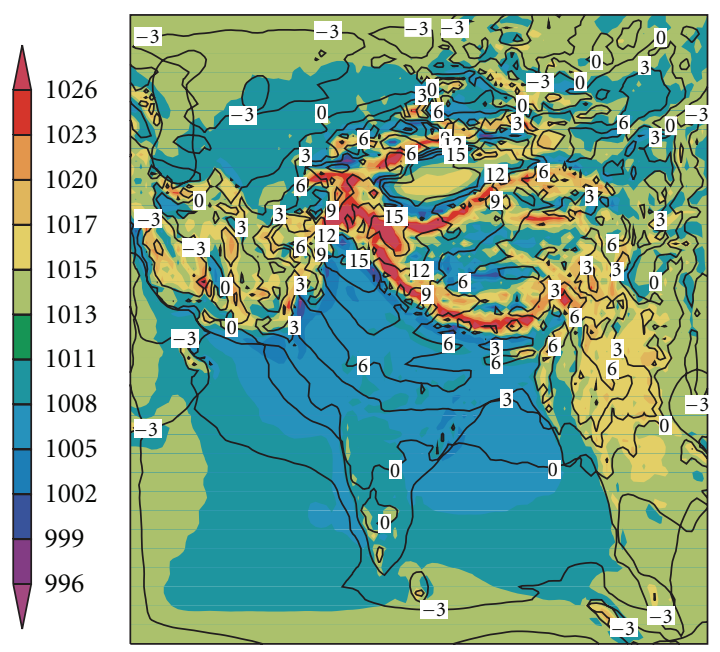

(b)

FIgURE 2: Mean sea level pressure (hPa; shaded) and geopotential height at $500 \mathrm{hPa}$ (gpm; contour lines) for HIRHAM (a) and the difference "HIRHAM-ERA40" (b); summer monsoon (JJAS) 1958-2001.

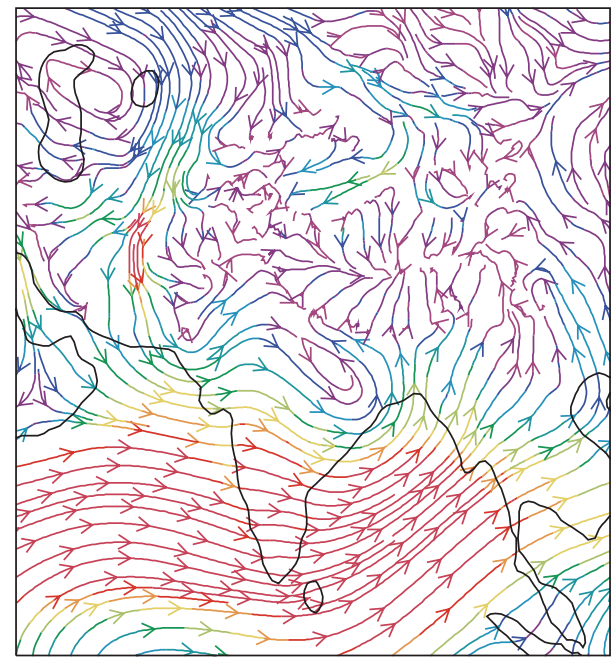

(a)

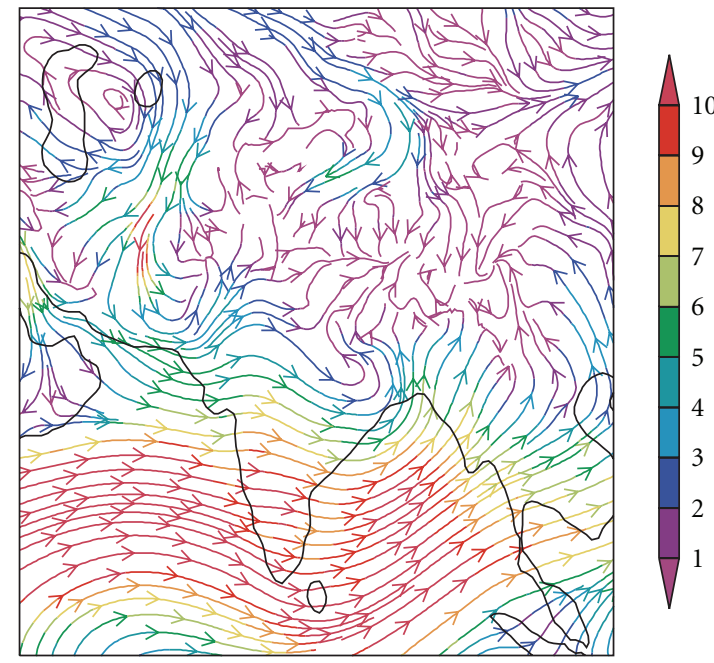

(b)

FIGURE 3: Mean wind fields (wind vectors) and wind speed at $850 \mathrm{hPa}(\mathrm{m} / \mathrm{s}$; colours) for HIRHAM (a) and ERA40 (b); summer monsoon (JJAS) 1958-2001.

level pressure (MSLP) and from $-5 \mathrm{gpm}$ to $+5 \mathrm{gpm}$ for the $500-\mathrm{hPa}$ geopotential height. In the mountain areas, the differences are larger: within $\pm 8 \mathrm{hPa}$ for mean sea level pressure and up to $+15 \mathrm{gpm}$ for the $500-\mathrm{hPa}$ geopotential height. Since surface pressure over Tibetan Plateau is inhomogeneous, the 500-hPa geopotential height is the first level not affected by the Himalayan topography. The MSLP over the Tibetan Plateau may be biased as a result of different topographies between ERA40 and HIRHAM due to the extrapolation of pressure levels larger than $500 \mathrm{hPa}$. Related to the different horizontal resolutions between the HIRHAM model $(\sim 50 \mathrm{~km})$ and ERA40 $(\sim 125 \mathrm{~km})$, the orography in HIRHAM is represented more realistically than in ERA40.
These differences in topography are reflected in larger circulation differences in mountain areas.

The good agreement in the mean near-surface largescale atmospheric circulation between HIRHAM and ERA40 within the entire integration domain is demonstrated by a high pattern correlation coefficient (0.95), a small bias $(0.5 \mathrm{hPa})$, and a small RMSE $(1.5 \mathrm{hPa})$ for the MSLP (see Table 2). The influence of the differently resolved orography between HIRHAM and ERA40 with resulting MLSP anomalies in the mountain regions becomes obvious by calculating the regional statistics for different subdomains. Compared to "ALL", the BIAS (2.0 hPa) and the RMSE (2.9 hPa) are higher for "ELEV1500", while the pattern correlation is lower (0.80). 


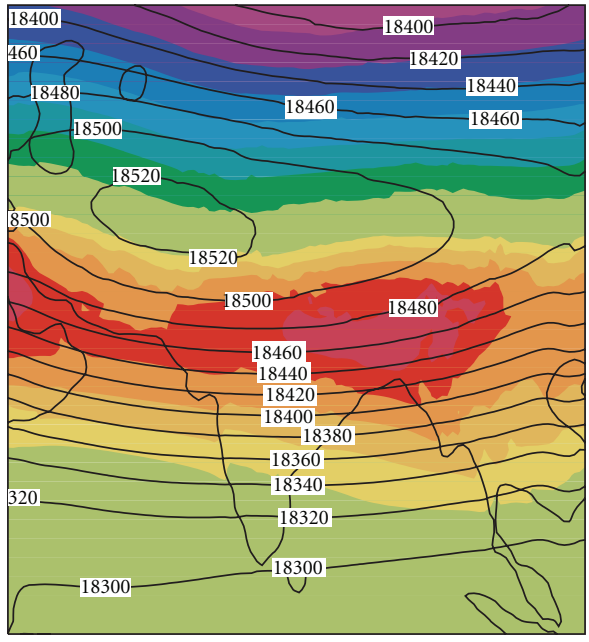

(a)

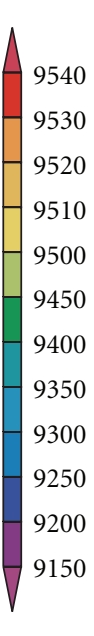

530

9520

9510

500

9450

400

350

300

250

200

9150

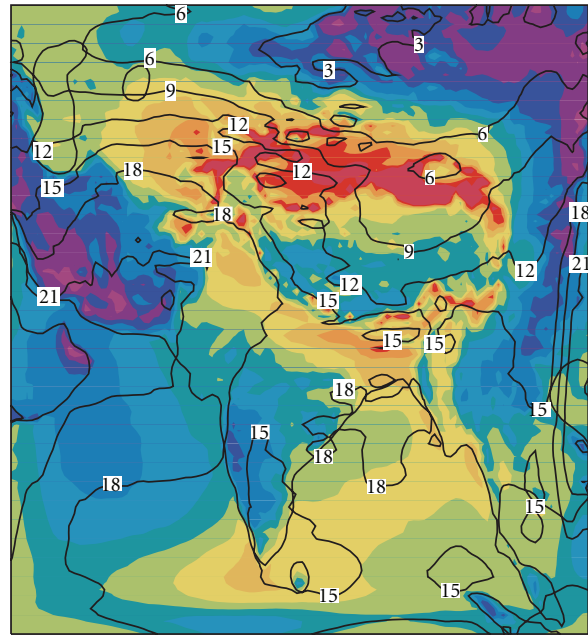

(b)

FIgURE 4: Geopotential height at $300 \mathrm{hPa}$ (gpm; shaded) and geopotential height at $70 \mathrm{hPa}$ (gpm; contour lines) for HIRHAM (a) and the difference "HIRHAM-ERA40" (b); summer monsoon (JJAS) 1958-2001.

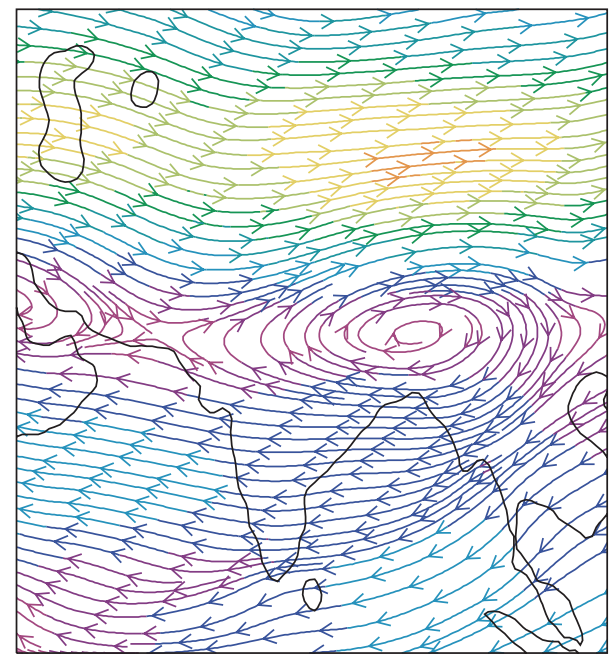

(a)

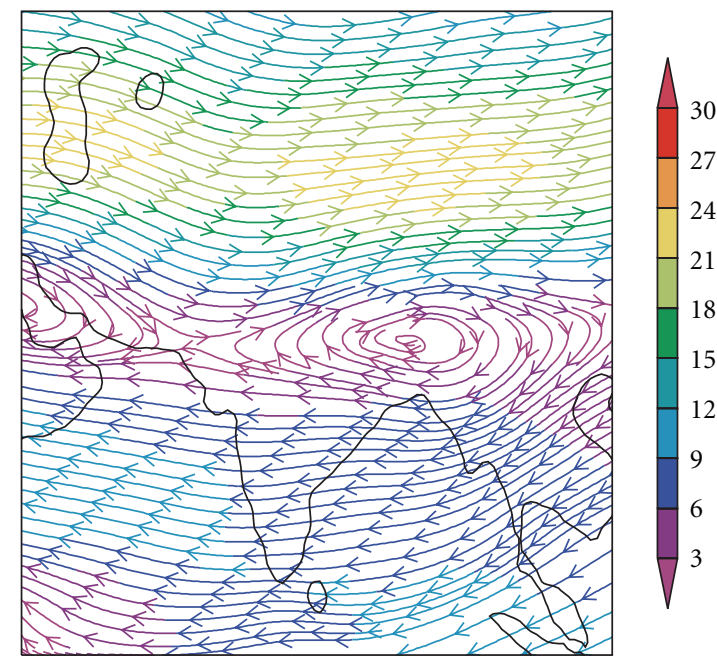

(b)

FIGURE 5: Mean wind fields (wind vectors) and wind speed at $300 \mathrm{hPa}(\mathrm{m} / \mathrm{s}$; colours) for HIRHAM (a) and ERA40 (b); summer monsoon (JJAS) 1958-2001.

On the contrary, the BIAS $(0.1 \mathrm{hPa})$ and RMSE $(0.6 \mathrm{hPa})$ are smaller for "SEA" showing a higher PATCOR (0.99) than in the entire domain (see Table 2).

The lower troposphere is characterized by a strong low-level southwestern wind field onto the coastlines of South Asia across the Arabian Sea and the Bay of Bengal, representing the Cross Equatorial Jet (CEJ) in Figure 3. HIRHAM and ERA40 show very similar patterns in the climatological low-level $(850 \mathrm{hPa})$ wind fields. The higher resolved HIRHAM model topography affects the regional wind systems in the highly elevated region.

The simulated geopotential heights at $300-\mathrm{hPa}$, shown in Figure 4, are affected by an upper tropospheric anticyclone located over the Tibetan Plateau. At its northern boundary, the Circumpolar Westerlies (CPW) are the significant flow patterns. South of that anticyclone, the upper tropospheric Tropical Easterly Jet (TEJ) occurs. All these patterns are well reproduced in HIRHAM, also visible in the comparison of the climatological upper troposphere $300 \mathrm{hPa}$ wind fields shown in Figure 5. In comparison with ERA40 data, the geopotential differences in Figure 4 are small, within $\pm 10 \mathrm{gpm}$ for the geopotential height in $300 \mathrm{hPa}$ and up to $+20 \mathrm{gpm}$ for the $70-\mathrm{hPa}$ geopotential height in lower stratosphere.

Compared to ERA40 data, the mean atmospheric largescale circulation is well reproduced by the HIRHAM model. Differences are mainly associated with a different horizontal resolution, where HIRHAM contributes with an added value 


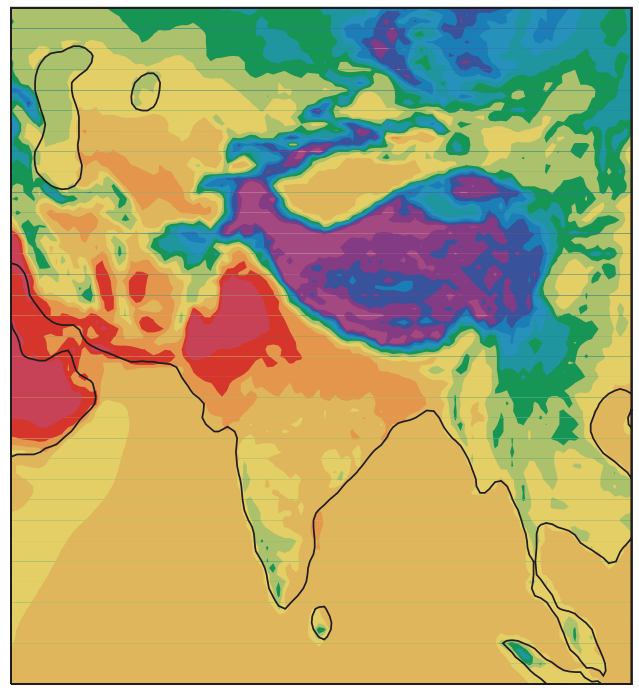

(a)

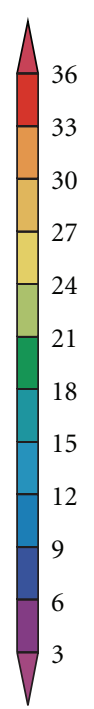

$-\begin{aligned} & 36 \\ & 33 \\ & 30 \\ & 27 \\ & 24 \\ & 21 \\ & 18 \\ & 15 \\ & 12 \\ & 9 \\ & 6 \\ & 3\end{aligned}$

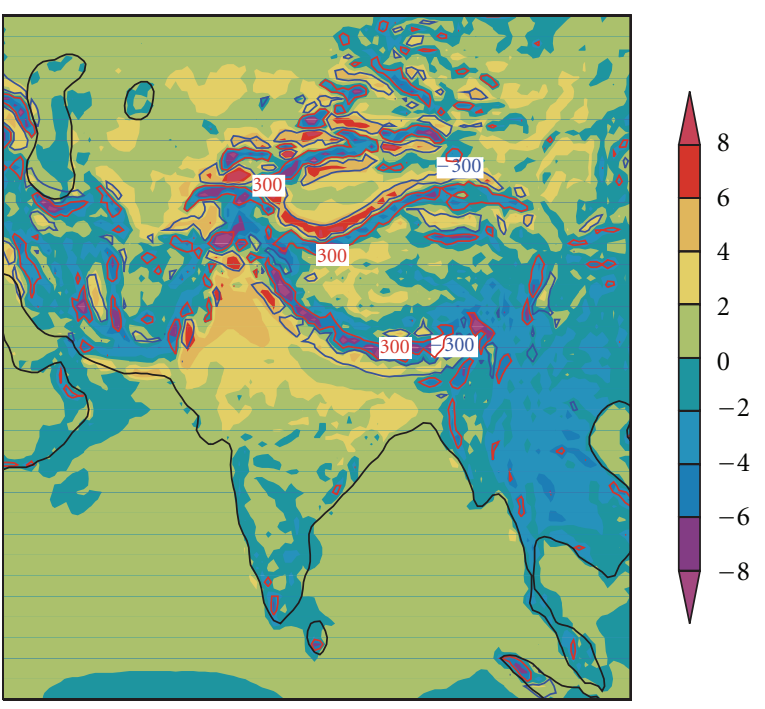

(b)

Figure 6: $2 \mathrm{~m}$ air temperature $\left({ }^{\circ} \mathrm{C}\right.$; shaded) for HIRHAM (a) and the difference "HIRHAM-ERA40" (b); summer monsoon (JJAS) 19582001. Additionally, the elevation differences "HIRHAM-ERA40" (m; contour lines) are shown in the right panel.

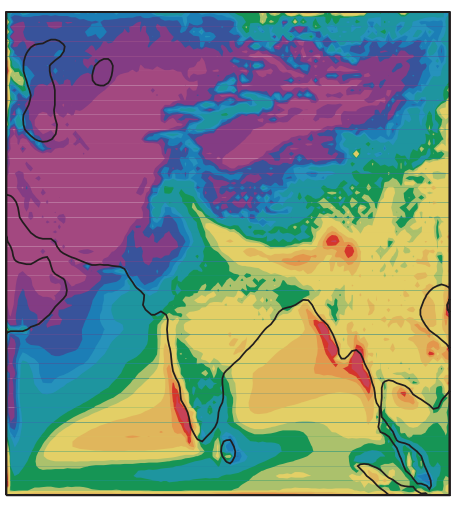

(a)
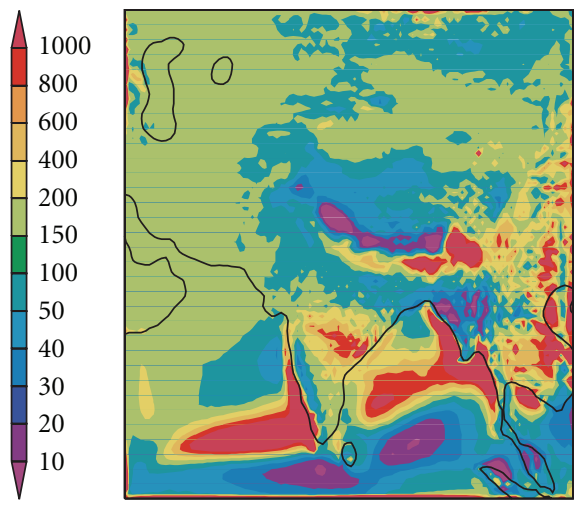

(b)

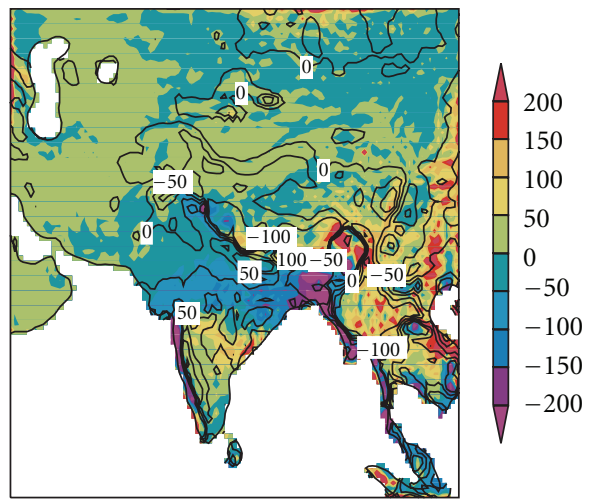

(c)

Figure 7: Precipitation (mm; shaded) for HIRHAM (a), the difference "HIRHAM-ERA40" (b), and the differences "HIRHAM-GPCC4" ((c); shaded) and "GPCC4-ERA40" ((c); contour lines); summer monsoon (JJAS) 1958-2001.

due to the better spatial resolution in agreement with other Asian RCM applications (e.g., [6, 9-13, 33]).

3.2. Temperature. The near-surface $2 \mathrm{~m}$ air temperature has been validated against the seasonal mean ERA40 reanalysis data averaged over the simulation period 1958-2001 for the summer monsoon season (JJAS).

The highest summer temperatures, presented in Figure 6, occur in the Tharr desert in northwestern India and the Arabian Peninsula. A well-pronounced temperature gradient between the warm flat land areas of India and the colder elevated mountain regions of Tibetan Plateau is simulated. Small differences between $-2 \mathrm{~K}$ and $+2 \mathrm{~K}$ occur in most parts of the domain (Figure 6(b)). In the mountains, higher temperature differences (within $\pm 8 \mathrm{~K}$ ) are calculated, which is attributed to the differently resolved orography. The topography-related temperature differences between
HIRHAM and ERA40 become also obvious by examining selected statistical parameters represented in Table 2. For the entire domain "ALL", a high pattern correlation coefficient (0.96), a small bias $(0.3 \mathrm{~K})$ and a small RMSE $(2.3 \mathrm{~K})$ occur. In "ELEV1500", larger values for BIAS $(-1.7 \mathrm{~K})$ and RMSE $(3.5 \mathrm{~K})$ and a lower PATCOR $(0.90)$ appear, similar to that discussed for MSLP.

\subsection{Precipitation}

3.3.1. Climatology. Due to summer monsoon circulation and orographic uplifting processes, intensive and long-term rainfall events occur especially in the windward of the mountains and the offshore coastal regions. Therefore the maxima of accumulated summer precipitation with more than $800 \mathrm{~mm}$ are observed in the windward of the Western Ghats at the Malabar Coast, at the southern slopes of 


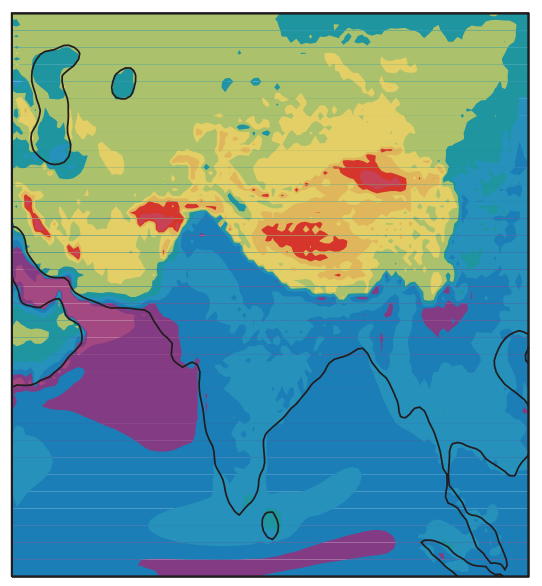

(a)

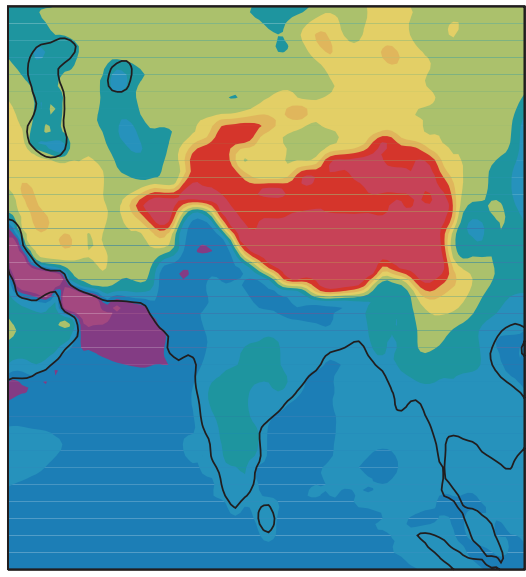

(b)

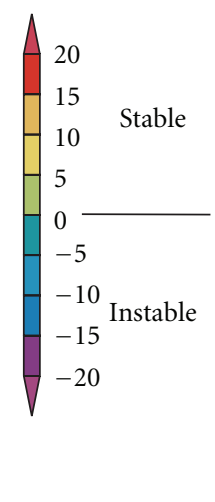

FIgURe 8: Potential convective instability (K) for HIRHAM (a) and ERA40 (b); summer monsoon (JJAS) $1990-2000$.

TABle 1: Gridded observed data sets used for validation of mean sea level pressure (1), geopotential (2), temperature (3), wind (4), and precipitation (5).

\begin{tabular}{lccccccc}
\hline $\begin{array}{l}\text { Dataset } \\
\text { name }\end{array}$ & $\begin{array}{c}\text { Horizontal } \\
\text { Resolution }\end{array}$ & $\begin{array}{c}\text { Number of } \\
\text { grid points }\end{array}$ & Longitude & Latitude & Period & $\begin{array}{c}\text { Temporal } \\
\text { resolution }\end{array}$ & Source \\
\hline ERA40 $0^{1,2,3,4,5}$ & $1.125^{\circ}$ & $320 \times 80$ & $0-360$ global & $90-90$ global & $1957-2002$ & monthly & $\begin{array}{c}\text { Combined (Gauge+Satellite) } \\
\text { ECMWF }\end{array}$ \\
GPCC4 $^{5}$ & $0.5^{\circ}$ & $720 \times 360$ & $0-360$ global & $90-90$ global & $1901-2006$ & monthly & $\begin{array}{c}\text { Gauge (land surface) } \\
\text { German Weather Service } \\
\text { Gauge (land surface India) } \\
\text { IMD-RF }\end{array}$ \\
\hline
\end{tabular}

Himalayas (Khasi Mountains and Shillong Plateau) and in the southwestern windward of the Burman mountain ranges in the eastern Bay of Bengal. These three zones are well reproduced by HIRHAM (see Figure 7). On the other side, lee effects cause less rainfall amounts below $100 \mathrm{~mm}$, seen for example in the Dekkan Plateau. The smallest amounts below $10 \mathrm{~mm}$ are simulated in the desert and semidesert areas. The precipitation validation has been carried out with seasonal mean ERA40 reanalysis data averaged over the simulation period 1958-2001 for the summer monsoon season (JJAS). Furthermore, GPCC4 and IMD-RF data have been used as additional gridded data sets.

In comparison with ERA40 (Figure 7(b)), mostly there are differences from $-50 \mathrm{~mm}$ to $+50 \mathrm{~mm}$ and higher differences in those regions, where the main part of summer precipitation occurs. HIRHAM underestimates precipitation at the southern slopes of Himalayas by ca. $-200 \mathrm{~mm}$ and shows an overestimation by ca. $+200 \mathrm{~mm}$ in the Khasi Mountains and Shillong Plateau southeastern of Himalayas near Assam, attributed to the smoothed orography in ERA40 due to the coarser horizontal resolution. The statistical parameters (see Table 2) show a relatively high pattern correlation coefficient $(0.75)$, a BIAS of $27.4 \mathrm{~mm}$, and a RMSE of $128.5 \mathrm{~mm}$ for "ALL". The subdomains are characterized by a pronounced differentiation with higher BIAS and RMSE especially for "SEA". There is a significant dipole pattern of dry precipitation differences located south of Ceylon and the southern Bay of Bengal with amounts below $-200 \mathrm{~mm}$ and humid differences west of Malabar Coast over Arabian Sea and the central Bay of Bengal with more than $+200 \mathrm{~mm}$ (see Figure $7(\mathrm{~b})$ ). That dipole pattern is associated with the weaker pattern correlation over "SEA" (see Table 2). To understand this anomaly pattern, a sensitivity study concerning the impact of the lateral boundary zone of different widths has been carried out (see the appendix).

Precipitation is strongly affected by topography [34], and that underlines the need for a high resolution in HIRHAM. Related to the better spatial resolution $\left(0.5^{\circ}\right)$ and the large number of assimilated land surface stations, GPCC4 is better suited to validate the HIRHAM-simulated precipitation than ERA40. There are smaller differences "HIRHAM-GPCC4" (Figure 7(c)) compared to "HIRHAMERA40". The pronounced negative difference at the southern Himalayan slopes found in the comparison to ERA40 is almost missing. Therefore, the HIRHAM-simulated precipitation is closer to the GPCC4 precipitation in the higher elevated regions, verified by a lower bias $(4.1 \mathrm{~mm})$ and a lower RMSE $(73.3 \mathrm{~mm})$. Higher pattern correlations for "HIRHAM versus GPCC4" in "ELEV1500" (0.85) and "INDIA" (0.81) compared to "GPCC4 versus ERA40" in "ELEV1500" (0.60) and "HIRHAM versus ERA40" in "INDIA" (0.77) show superiority of high-resolution model that is the added value of the HIRHAM simulations (see Table 2). 


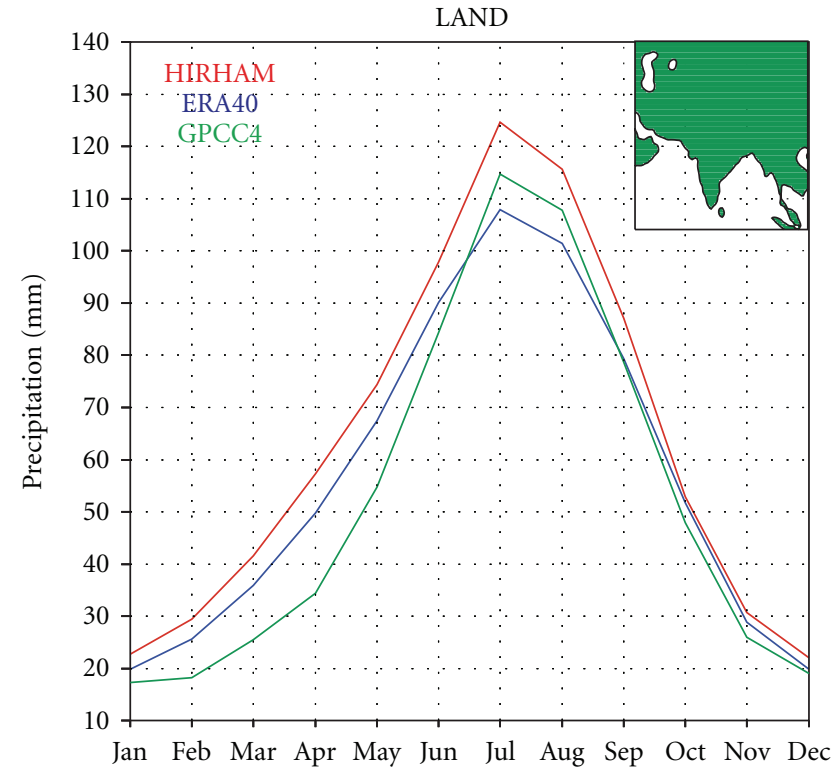

(a)

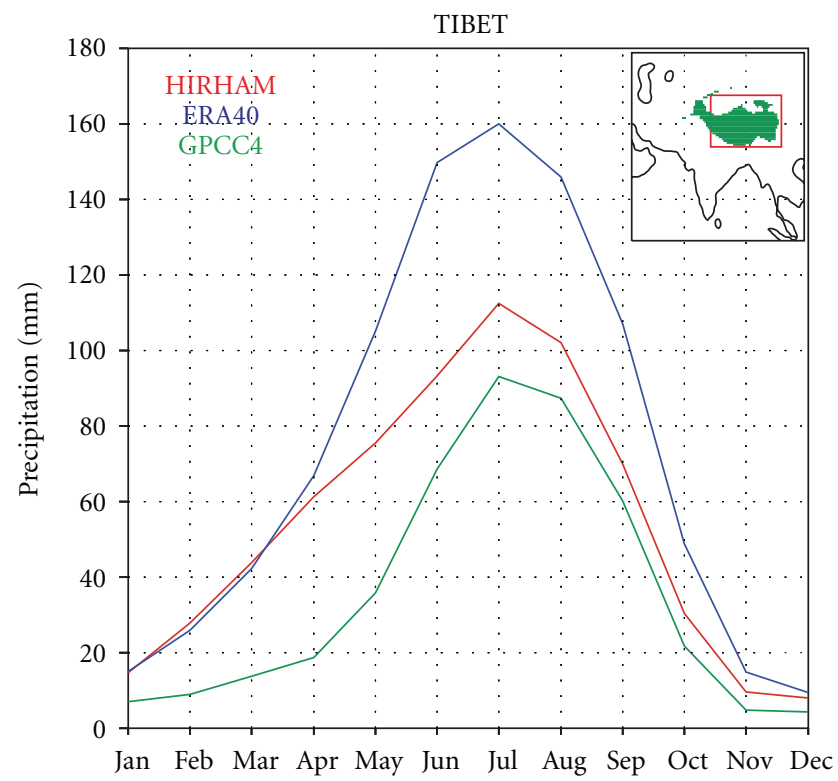

(c)

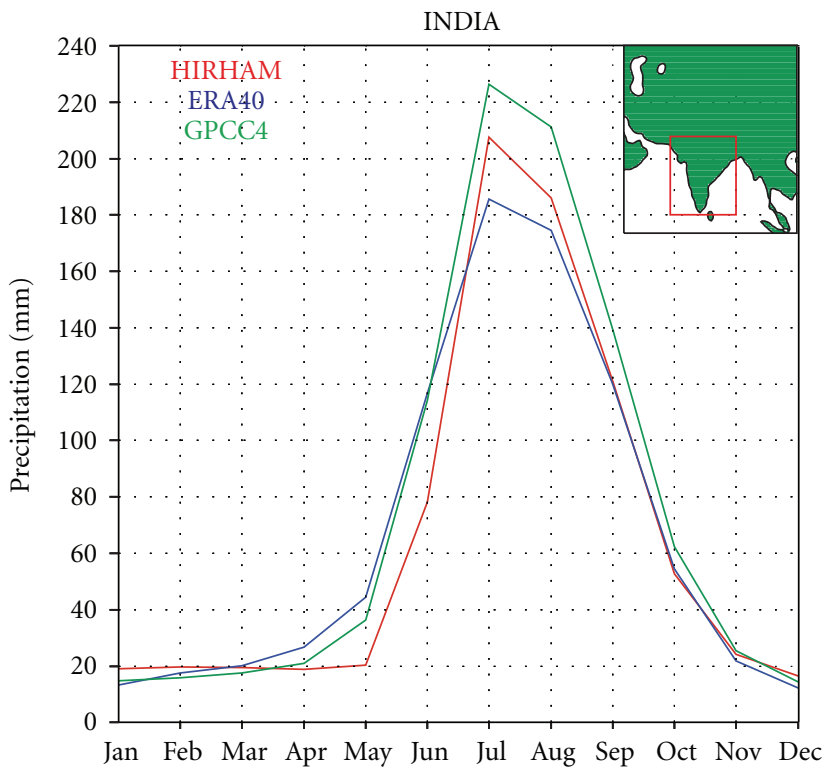

(b)

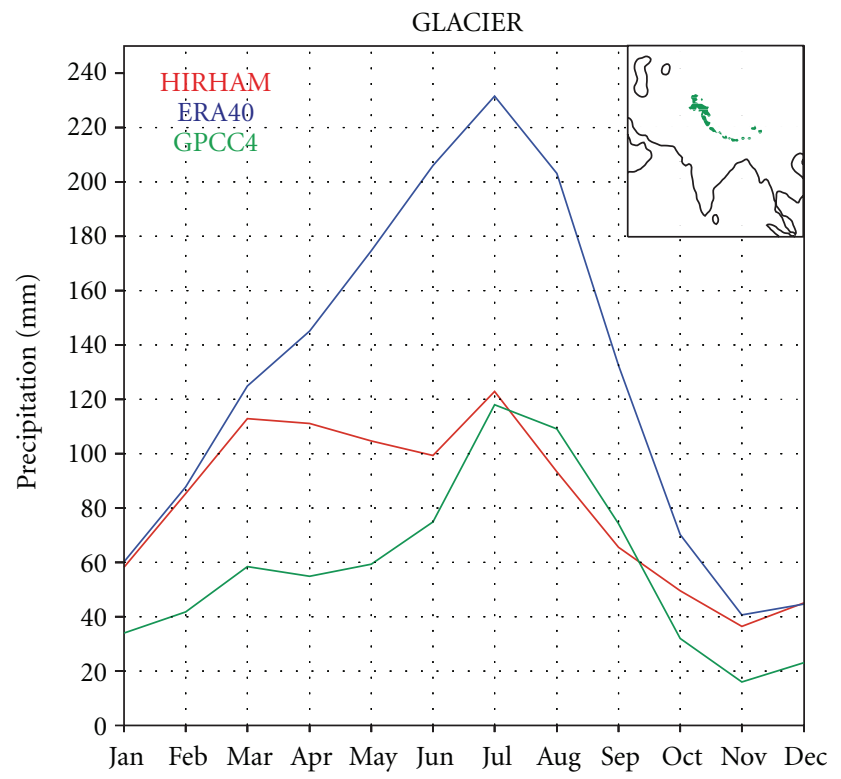

(d)

Figure 9: Mean annual cycles of precipitation (mm) 1958-2001 for HIRHAM (red), ERA40 (blue), and GPCC4 (green) in selected subdomains.

Summer monsoon precipitation is partly affected by convective rainfall events. Therefore, dynamical processes, which impact on convection, have been analyzed. According to that an index of potential convective instability for the last decade (1990-2000) has been calculated for HIRHAM and ERA40, to describe and compare the dynamical mechanisms of the rainfall patterns in summer (see Figure 8). The index [35] is based on the difference of the equivalent potential temperature between $700 \mathrm{hPa}$ and $1000 \mathrm{hPa}$. Positive values represent stable tropospheric conditions, and negative values indicate the potential convective instability of the lower troposphere, which is a crude indicator of convection and rainfall in summer. The entire Indian Ocean and the land surface south of Tibetan Plateau and Himalayas are characterized by instable conditions with minima in the northern Arabian Sea. Comparing the HIRHAM and ERA40 potential convective instability indices, the patterns in HIRHAM show more regional features over high topography due to the higher horizontal resolution. The central Indian land areas and the northern Arabian Sea are represented by a stronger instability than in ERA40 related to a higher potential convective activity characterized by positive anomalies in both "precipitation minus evaporation" and vertical velocity at $500 \mathrm{hPa}$ and more total rainfall in this area. That result 
TABLE 2: Statistical parameters for HIRHAM model and observed data sets for mean sea level pressure (MSLP), 2m air temperature (T2m), and precipitation (Precip) in the entire model domain (ALL) and selected subdomains: mountain area $>1500 \mathrm{~m}$ a.s.l. (ELEV1500), ocean (SEA), land surface (LAND) and Indian continent (INDIA), defined as pattern correlation coefficient (PATCOR), difference "HIRHAM model minus observation", or the difference between two observational data sets (BIAS) and root mean square error (RMSE) in hPa (MSLP), $\mathrm{K}(\mathrm{T} 2 \mathrm{~m})$ and $\mathrm{mm}$ (Precip).

\begin{tabular}{|c|c|c|c|c|c|c|}
\hline Datasets & Time average & Parameter & Domain & Patcor & Bias & RMSE \\
\hline \multirow{5}{*}{ HIRHAM versus ERA40 } & \multirow{5}{*}{$1958-2001$} & \multirow{5}{*}{ MSLP } & ALL & 0.95 & 0.5 & 1.5 \\
\hline & & & ELEV1500 & 0.80 & 2.0 & 2.9 \\
\hline & & & SEA & 0.99 & 0.1 & 0.6 \\
\hline & & & LAND & 0.94 & 0.7 & 1.8 \\
\hline & & & INDIA & 0.93 & -0.2 & 5.9 \\
\hline \multirow{5}{*}{ HIRHAM versus ERA40 } & \multirow{5}{*}{ 1958-2001 } & \multirow{5}{*}{$\mathrm{T} 2 \mathrm{~m}$} & ALL & 0.96 & 0.3 & 2.3 \\
\hline & & & ELEV1500 & 0.90 & -1.7 & 3.5 \\
\hline & & & SEA & 0.93 & 0.4 & 0.7 \\
\hline & & & LAND & 0.95 & 0.2 & 2.8 \\
\hline & & & INDIA & 0.93 & 1.9 & 10.7 \\
\hline \multirow{5}{*}{ HIRHAM versus ERA40 } & \multirow{5}{*}{$1958-2001$} & \multirow{5}{*}{ Precip } & ALL & 0.75 & 27.4 & 128.5 \\
\hline & & & ELEV1500 & 0.72 & -15.5 & 88.3 \\
\hline & & & SEA & 0.69 & 65.3 & 181.5 \\
\hline & & & LAND & 0.79 & 8.8 & 91.8 \\
\hline & & & INDIA & 0.77 & 42.7 & 250.6 \\
\hline \multirow{5}{*}{ HIRHAM versus GPCC4 } & \multirow{5}{*}{ 1958-2001 } & \multirow{5}{*}{ Precip } & ALL & 0.79 & 10.4 & 94.8 \\
\hline & & & ELEV1500 & 0.85 & 4.1 & 73.3 \\
\hline & & & SEA & \multicolumn{3}{|c|}{ None comparable grid points } \\
\hline & & & LAND & 0.80 & 6.5 & 89.3 \\
\hline & & & INDIA & 0.81 & 38.6 & 244.7 \\
\hline \multirow{5}{*}{ GPCC4 versus ERA40 } & \multirow{5}{*}{$1958-2001$} & \multirow{5}{*}{ Precip } & ALL & 0.82 & -1.9 & 75.0 \\
\hline & & & ELEV1500 & 0.60 & -8.4 & 97.1 \\
\hline & & & SEA & \multicolumn{3}{|c|}{ None comparable grid points } \\
\hline & & & LAND & 0.80 & -0.6 & 70.8 \\
\hline & & & INDIA & 0.74 & -0.1 & 95.7 \\
\hline
\end{tabular}

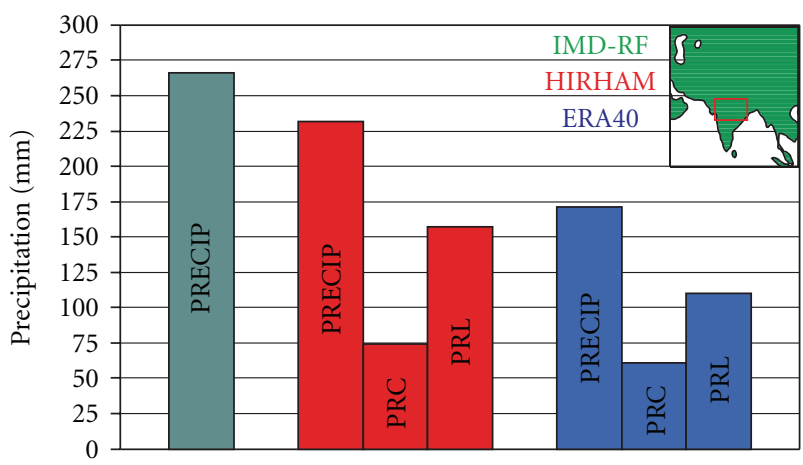

Figure 10: Precipitation (mm) for IMD-RF (green), HIRHAM (red), and ERA40 (blue) in a selected box of Indian land surface; summer monsoon (JJAS) 1958-2001: PRECIP = total precipitation, $\mathrm{PRC}=$ convective precipitation and $\mathrm{PRL}=$ large-scale precipitation .

agrees well with the increased rainfall over central India, which is closer to GPCC4 data set (see Figure 7) and demonstrates the added value of HIRHAM in those regions.
The further inspection of the mean annual precipitation cycle shown in Figure 9 for selected subdomains (LAND, INDIA, TIBET, and GLACIER) over the long-term simulation period from 1958-2001 additionally emphasizes the added value of HIRHAM model against the driving ERA40 data. In "LAND" and "INDIA", there is a good agreement between HIRHAM, ERA40, and GPCC4 with small differences throughout the year. In the summer months, HIRHAM simulates larger precipitation than ERA40 and is thus closer to GPCC4. In the higher elevated regions, "TIBET" and "GLACIER", ERA40 shows a significant overestimation of precipitation particularly from May to September, that is, the whole summer monsoon season. Related to its better spatial resolution, HIRHAM is able to simulate the precipitation more realistically, compared to GPCC4. The statistical parameters computed in Table 2 underline that added value of HIRHAM.

Furthermore, the validation of HIRHAM-simulated rainfall over central India with another rain-gauge-based high-resolution gridded data set from the Indian Meteorological Department (IMD-RF) supports the already discussed added value of the HIRHAM simulation in that 


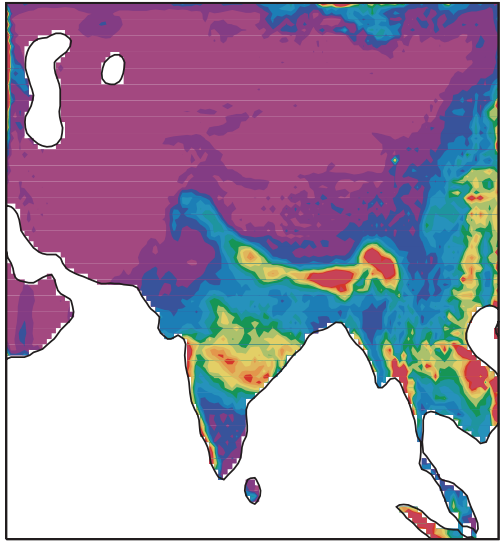

(a)

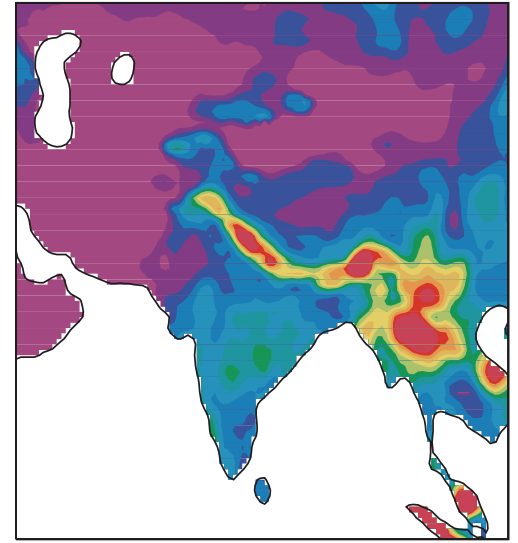

(b)

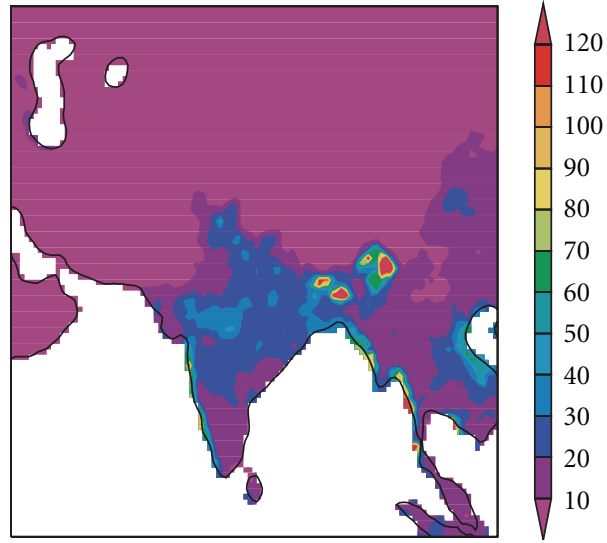

(c)

FIgURE 11: Standard deviation of precipitation (mm; shaded) for HIRHAM (a), ERA40 (b), and GPCC4 (c); summer monsoon (JJAS) 1958-2001.

region (Figure 10). An area mean over a domain covering the characteristic rainfall pattern over central Indian land surface has been analyzed for IMD-RF, HIRHAM, and ERA40. HIRHAM is closer to the IMD-RF $(266.1 \mathrm{~mm})$ data by simulating more total precipitation $(231.5 \mathrm{~mm})$ than ERA40 $(171.1 \mathrm{~mm})$. The largest contribution to the rainfall originates from large-scale precipitation, and a smaller part is connected with convective precipitation. Both components are larger in the HIRHAM simulation compared to ERA40.

\subsubsection{Interannual Variability and Decadal Means. The inter-} annual variability, described by the standard deviation over the simulation period 1958-2001 for the summer monsoon season (JJAS) is presented for the precipitation in Figure 11. For a better comparison with GPCC4 land data set, only the values over the land area are shown. All data sets agree on a high year-to-year precipitation variability over the Western Ghats, central India, the southern slopes of Himalayas including Khasi Mountains and Shillong Plateau and over southeastern Asia. Compared to GPCC4, HIRHAM and ERA40 overestimate the interannual precipitation variability with values of up to more than $100 \mathrm{~mm}$. A low variability is found over extratropical latitudes north of $30^{\circ} \mathrm{N}$ including Tibetan Plateau, over the Arabian Peninsula as well as over the desert and semidesert areas south of Caspian Sea.

Figure 12 represents the mean precipitation over the land areas for two selected 10-year periods within the whole 44-year-long HIRHAM simulation. The first decade (19701980) is according to [32] characterized by more wet and the second period (1990-2000) by normal summer monsoon rainfall conditions. In both decades, the HIRHAM precipitation resembles the GPCC4 data set quite well, especially over southern and central India, and over eastern Himalayas (Khasi Mountains and Shillong Plateau). Therefore, not only with respect to the long-term climatology but also on decadal time scales, the added value of HIRHAM compared to ERA40 has been demonstrated.
3.3.3. Wet and Dry Summer Monsoon Composites. After the successful validation of HIRHAM simulations with respect to the long-term and decadal climatology, extreme summer monsoon precipitation for individual years has been analyzed. The aim is to investigate the HIRHAM performance in simulating typical rainfall anomaly patterns between strong (wet) and weak (dry) monsoon (years). The selection of the anomalous wet and dry composites from the long-term simulation 1958-2001 is done by the criteria of Farrara and $\mathrm{Yu}[36]$. Monsoon years are defined as anomalous wet (dry) if the summer (JJAS) precipitation averaged over the monsoon domain [35] is more (less) than 0.5 standard deviations above (below) the climatological mean.

In Figures 13(a)-13(c), the characteristic rainfall differences for "wet-dry" composite years (JJAS) are shown together with the same composites for ERA40 and GPCC4. The $95 \%$ statistical significance level of the differences is indicated by white contour lines. The HIRHAM simulations indicate a higher differentiation in the distribution of these patterns compared to ERA40. The negative precipitation anomaly over southern India is in better agreement comparing HIRHAM with GPCC4. With respect to the positive precipitation anomaly over central India and at the west coast of India, the HIRHAM simulation resembles the GPCC4 data set. The third positive precipitation anomaly found over south-eastern Asia is also reproduced by HIRHAM, while ERA40 fails to show it. On the other side, HIRHAM fails to reproduce the positive precipitation anomaly over the area of Bangladesh visible in GPCC4.

Figure 13(d) shows the "precipitation minus evaporation" and the vertical velocity at $500 \mathrm{hPa}$ for "wet-dry" composite years (JJAS) based on HIRHAM simulations. The white dots represent the areas of strongest potential convective activity related to the occurrence of positive anomalies "precipitation minus evaporation" as well as positive anomalies of vertical velocity at $500 \mathrm{hPa}$, for "wet-dry". It indicates that the three positive precipitation anomalies described in Figure 13(c) for the HIRHAM simulation are 

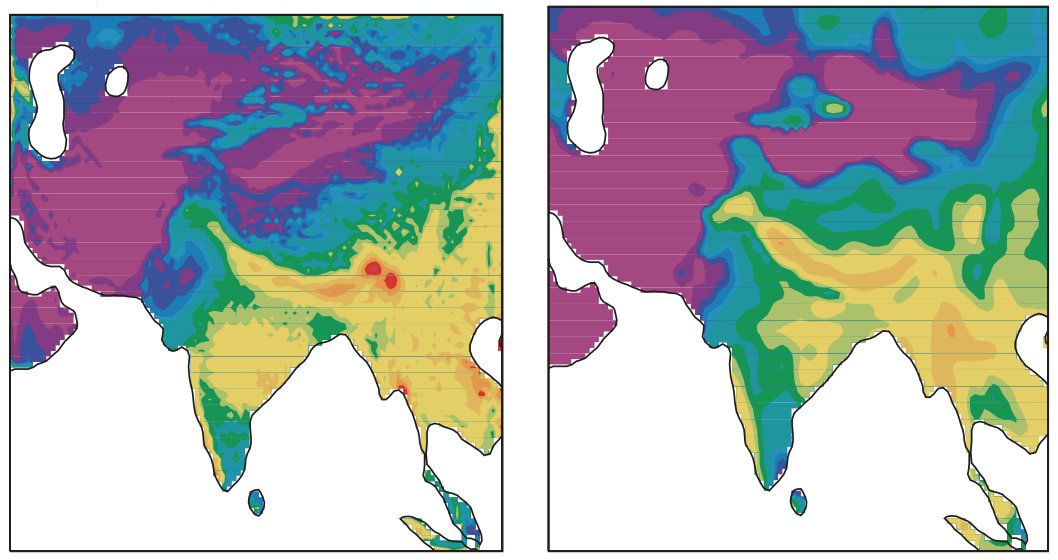

(a)
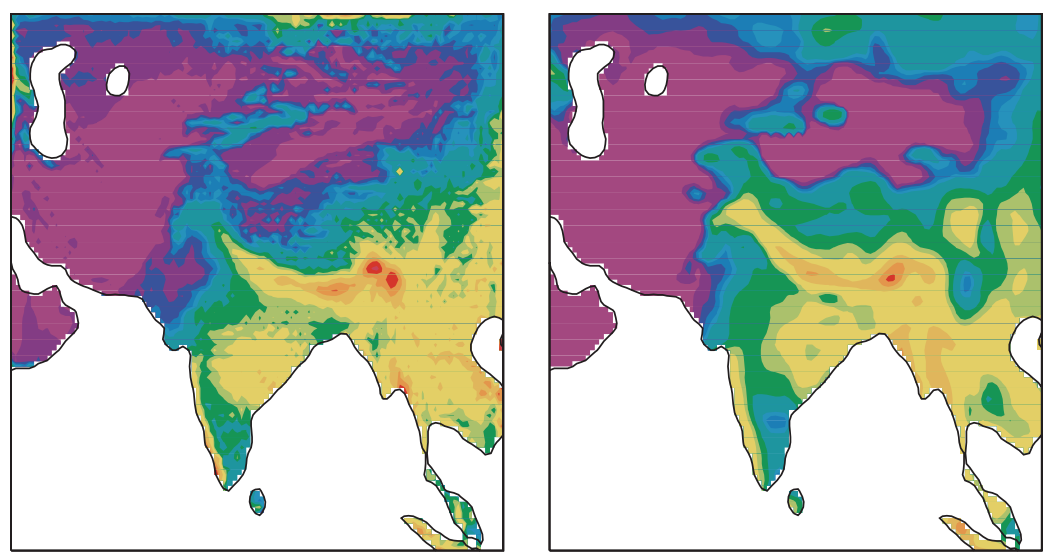

(b)
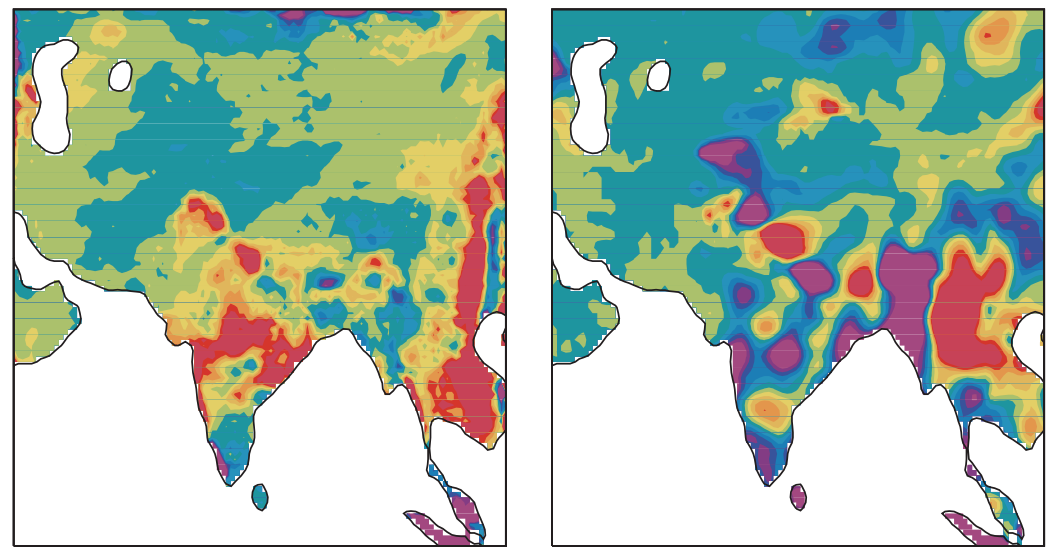

(c)
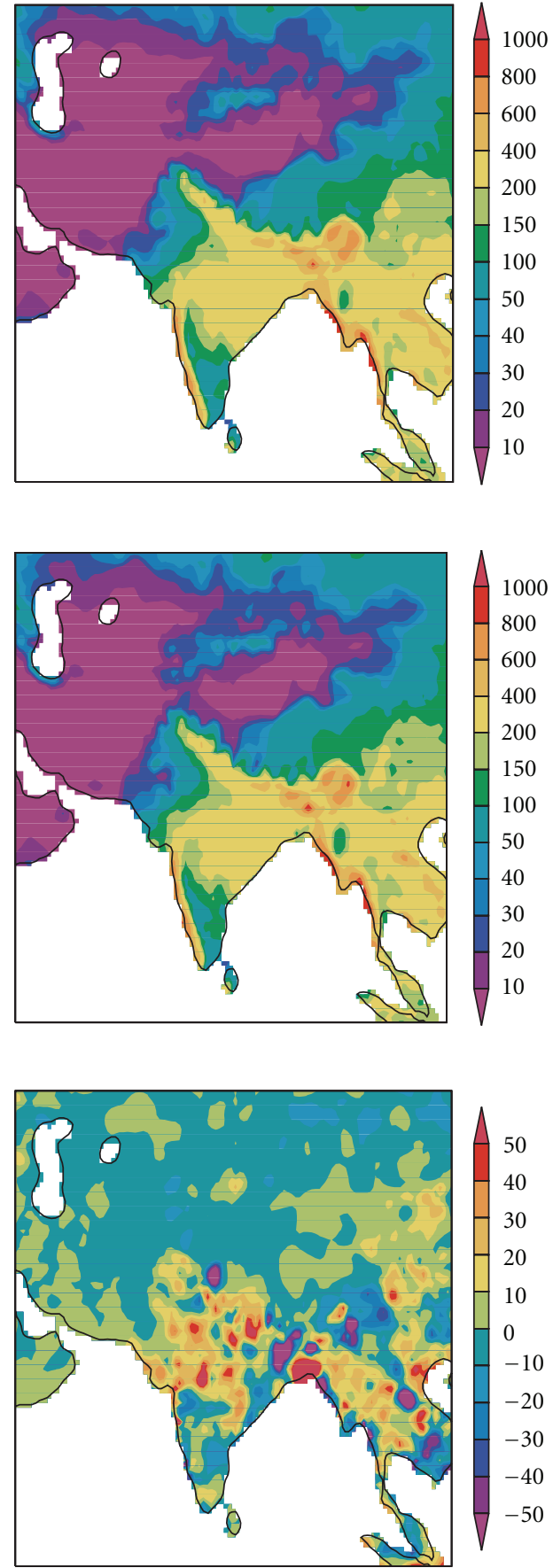

Figure 12: Precipitation (mm; shaded) for HIRHAM (left), ERA40 (middle) and GPCC4 (right); summer monsoon (JJAS) 1970-1980 (a), 1990-2000 (b) and the difference "1970-1980 minus 1990-2000" (c).

associated with those regions indicating that the complex feedbacks between convective and large-scale precipitation are reproduced by the HIRHAM simulations to some extent. Moist convection is important over warm oceanic and continental regions that extend from the tropics into the mid-latitudes and includes individual clouds from horizontal scales between 1 and $10 \mathrm{~km}$ to mesoscale convective systems with horizontal scales around $1000 \mathrm{~km}$. Convection affects the surface locally through heavy rains and through its aggregated effects on the large-scale atmospheric fluxes of momentum, moisture, and heat. Many atmospheric processes of varying scale influence the vertical thermodynamical atmospheric structure, in which convection is initiated. We computed a potential convective instability index, which is sensitive to the lower tropospheric moisture. The moisture content evolves according to a mixing ratio equation for 


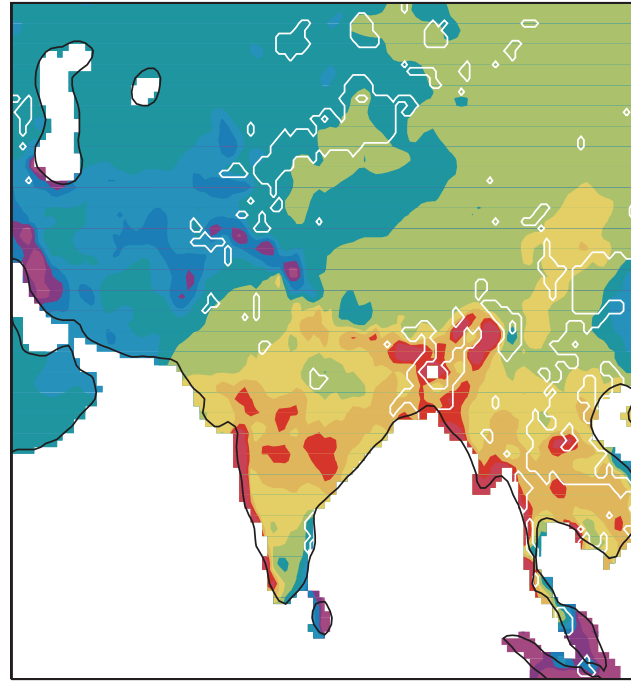

(a)

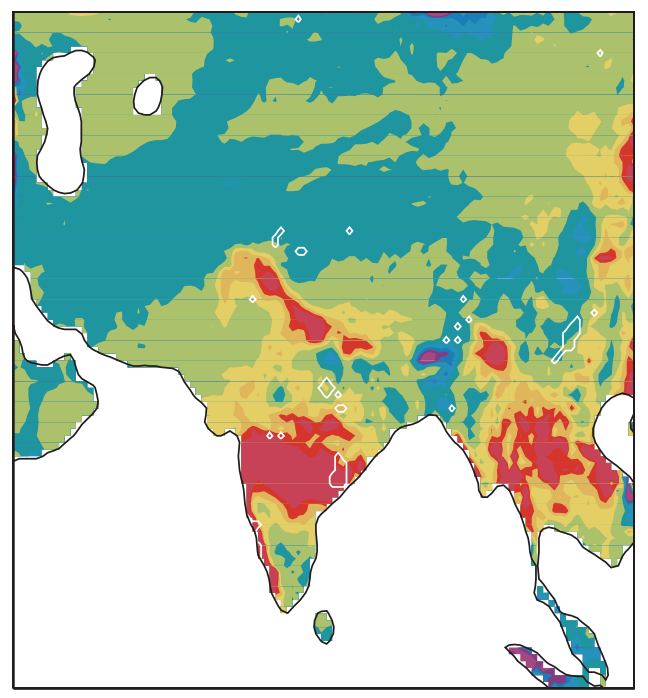

(c)
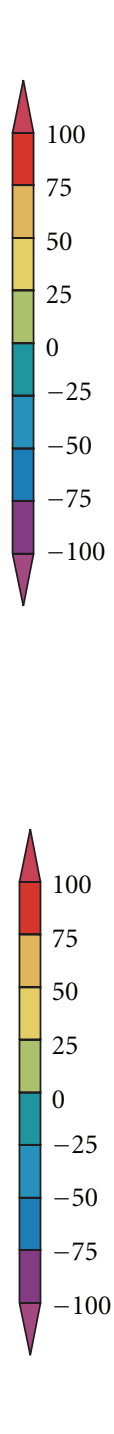

75

50

25

50

75

0$$
\text { . }
$$

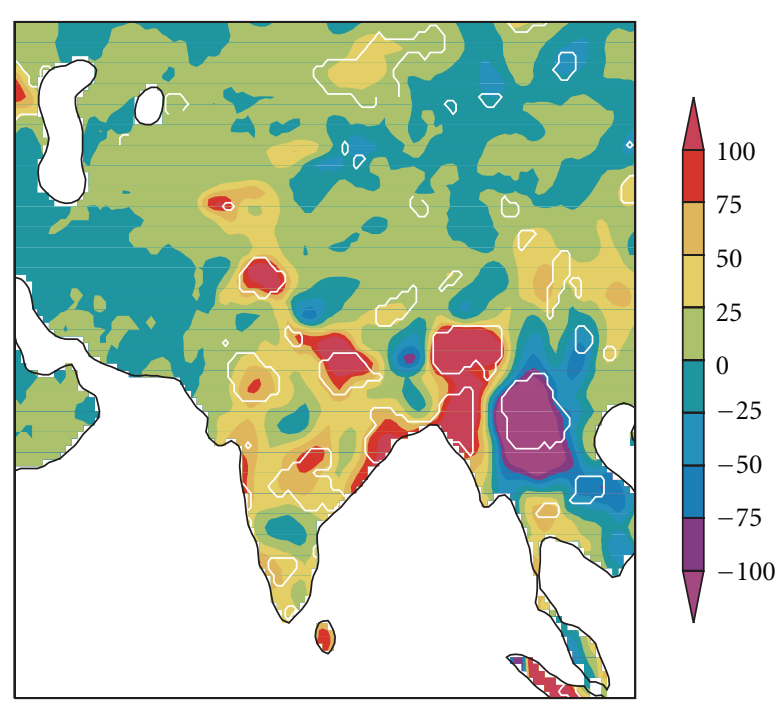

(b)

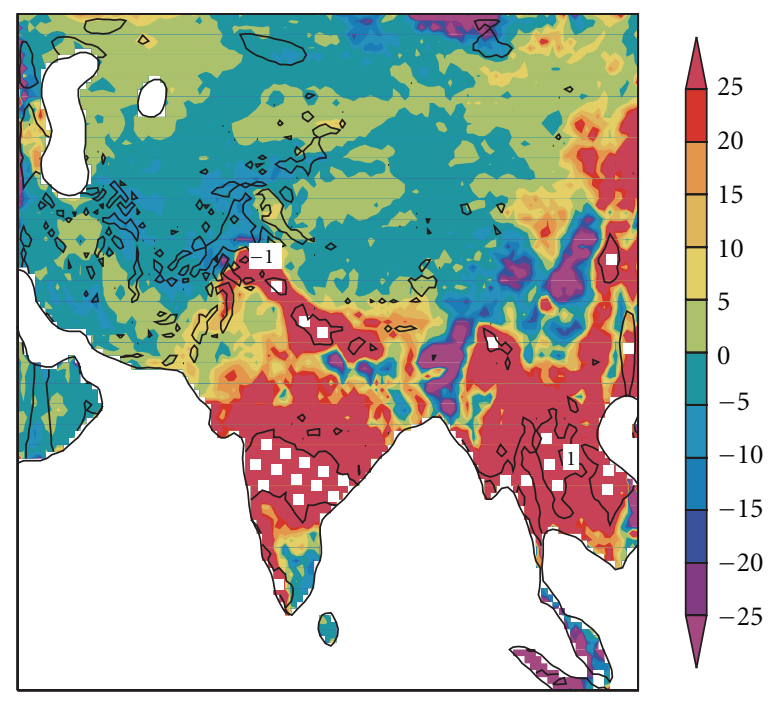

(d)

FIGURE 13: Precipitation "wet-dry" (mm; shaded) and statistical significance (95\%; white contour lines) for GPCC4 (a), ERA40 (b), and HIRHAM (c). Precipitation-Evaporation (P-E) "wet-dry" (mm; shaded) and vertical velocity ( $\omega)$ at $500 \mathrm{hPa}$ "wet-dry" (hPa/h; black contour lines) for HIRHAM (d); summer monsoon (JJAS) 1958-2001. White dots in (d) show areas with positive anomalies in both P-E and $\omega$.

water vapour. The local change of the mean mixing ratio depends on the horizontal and vertical advection of its mean components and on the horizontal and vertical flux convergences of its eddy component. Persistent large-scale ascent can saturate lower tropospheric layers. In this way, vertical motions induced by advective processes contribute to thermodynamical destabilisation in the vertical column. In the long-term mean, P-E is a measure of the column convergence of moisture, which is influenced by convection and the large-scale horizontal advection of moisture.

\section{Conclusions}

Simulations of the Indian summer monsoon circulation with the regional climate model HIRHAM have been represented and validated against several observational gridded data sets.
The performance of HIRHAM concerning the climatology and variability of atmospheric circulation, temperature, and precipitation has been quantified. A rather good agreement between model and ERA40 data in the circulation and temperature patterns has been found.

The validation of rainfall climatology and variability with several observational data sets (ERA40, GPCC4 and IMD$\mathrm{RF}$ ) indicated that the simulations show a better agreement with the higher-resolution data sets and can deliver an added value compared to ERA40. The improvement is due to spatial resolution and the model physics. HIRHAM delivers the best agreement with the GPCC4 precipitation data set. The HIRHAM-simulated precipitation is closer to the GPCC4 precipitation in the higher elevated regions. For example, the pronounced negative difference at the southern Himalayan slopes, which was obvious in comparison to 

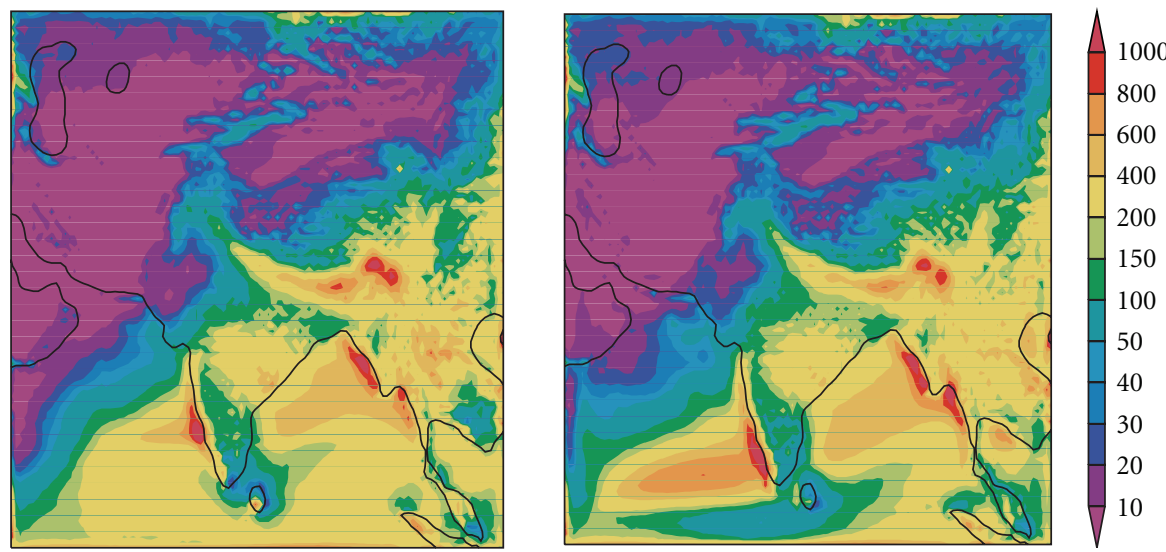

(a)
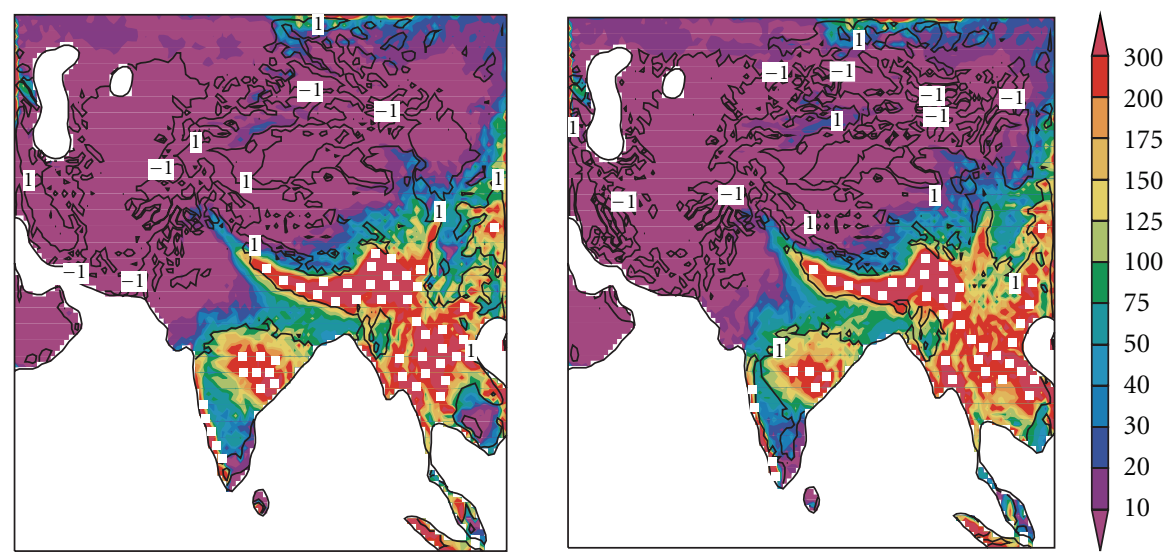

(b)
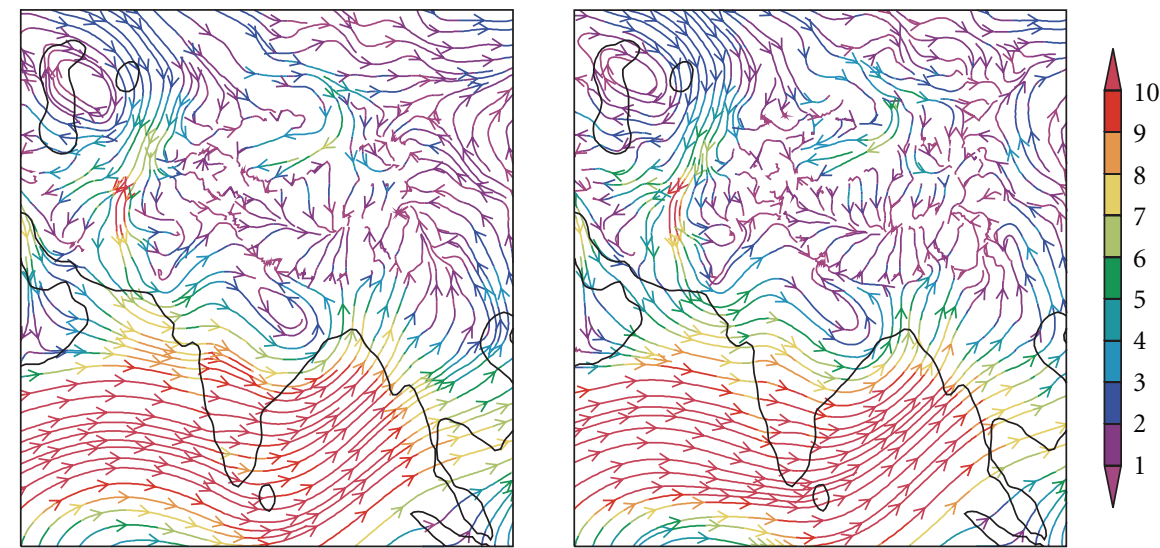

(c)

Figure 14: Precipitation ( $\mathrm{mm}$; shaded) (a), Precipitation-Evaporation (mm; shaded) and vertical velocity at $500 \mathrm{hPa}(\mathrm{hPa} / \mathrm{h}$; contour lines) (b), mean wind fields (wind vectors) and wind speed at $850 \mathrm{hPa}$ (m/s; colours) (c) for HIRHAM "BOUND20" (left) and HIRHAM "BOUND10" (right); summer monsoon (JJAS) 1990-2000. White dots in (b) show areas with positive anomalies in both P-E and $\omega$.

ERA40, is almost missing in the GPCC4 comparison. Over central India, there is a humid anomaly pattern "HIRHAMERA40", which becomes smaller in "HIRHAM-GPCC4". A higher pattern correlation for "HIRHAM versus GPCC4" in "INDIA" compared to "HIRHAM versus ERA40" shows the added value of the HIRHAM simulations over central India. The validation of the HIRHAM-simulated rainfall over central India with the rain-gauge-based high-resolution data set from the Indian Meteorological Department (IMD-RF) supports the discussed benefit of the HIRHAM simulation in that region.

Comparing the HIRHAM and ERA40 potential convective instability indices, the patterns in HIRHAM represent more regional features over the high topography due to 
the higher horizontal resolution. The central Indian land areas and the northern Arabian Sea are represented by a stronger instability than in ERA40 related to stronger potential convective activity characterized by positive anomalies "precipitation minus evaporation" as well as positive anomalies of vertical velocity at $500 \mathrm{hPa}$ and more total rainfall in this area. That result agrees well with the increased rainfall over central India, which is closer to GPCC4 data set.

The mean annual precipitation cycle has been investigated for selected subdomains over the long-term simulation period. In the higher elevated regions, "TIBET" and "GLACIER", ERA40 shows a significant overestimation of precipitation particularly from May to September. Related to its better spatial resolution, HIRHAM is able to simulate this precipitation more realistically, compared to GPCC4.

All data sets agree on a high year-to-year precipitation variability over the Western Ghats, central India, the southern slopes of Himalayas, and over southeastern Asia. Compared to GPCC4, HIRHAM and ERA40 overestimate the interannual precipitation variability. A low variability is found over extratropical latitudes north of $30^{\circ} \mathrm{N}$, well represented in all data.

After the successful validation of HIRHAM simulations with respect to the long-term and decadal climatology, the typical rainfall anomaly patterns between strong (wet) and weak (dry) monsoons (years) have been evaluated. The HIRHAM simulations indicate a higher differentiation in the distribution of these patterns compared to ERA40. The negative precipitation anomaly over southern India is in better agreement comparing HIRHAM with GPCC4. With respect to the positive precipitation anomaly over central India and at the west coast of India, the HIRHAM simulation resembles the GPCC4 data set. The third positive precipitation anomaly found over south-eastern Asia is also reproduced by HIRHAM, while ERA40 fails to show it. On the other side, HIRHAM fails to reproduce the positive precipitation anomaly over the area of Bangladesh visible in GPCC4. The simulated three positive precipitation anomalies are associated with areas of strongest potential convective activity characterized by positive anomalies in both $\mathrm{P}-\mathrm{E}$ and vertical velocity at $500 \mathrm{hPa}$ indicating that the complex feedbacks between convective and large-scale precipitation are reproduced by the HIRHAM simulations to some extent.

\section{Appendix}

Although we did not change the size of the integration domain like Castro et al. [4], this sensitivity study helps to understand the impact of different wide boundary zones on the simulation results. In an experiment (called HIRHAM "BOUND20"), the boundary relaxation has been expanded to a 20-grid-point-wide zone. The aim of this sensitivity study was to test its impact on the simulation results, since a significant dipole bias in the HIRHAM-simulated rainfall over the Indian Ocean near the equator occurred. A second aim was to study the impact of the changed boundary zone on the simulated convection and related rainfall patterns as well as the behaviour of wind fields near the southern boundary.

Figure 14(a) shows a significant weakening and northern shift of the rainfall dipole pattern. This demonstrates that part of the precipitation bias is connected with the lateral boundary forcing and the width of the boundary zone. According to other RCM studies (e.g., $[6,8-11,37]$ ), it is possible that another part contributing to the rainfall bias is associated with the cumulus convection parameterization. To explore this in detail is beyond the scope of this paper, but such HIRHAM sensitivity studies are planned for the future.

The characteristic rainfall pattern over central India (Figure 14(a)) and the distribution of strong convection over land surface (Figure 14(b)) are still present and independent of the applied boundary zone width.

Finally, the effect of the modified boundary zone on the wind fields at $850 \mathrm{hPa}$ shows a northern shift of the maximum monsoonal wind flow across the central and southern Arabian Sea, India, and the Bay of Bengal (see Figure 14(c)) with impacts on the northern shift of the precipitation anomaly dipole pattern over sea (see Figure 14(a)). The characteristic high gradient of wind speed, which normally occurs over southern India and the Bay of Bengal (see "BOUND10"), is also shifted to the north, where it is weakening concurrently.

\section{Acknowledgments}

This research was supported by the DFG-Graduate School 1364/1 "Interactions between Tectonics, Climate and Biosphere in the African-Asian monsoonal region" of the University of Potsdam funded by the German Science Foundation (DFG). The authors thank Professor Manfred Strecker, acting representative of the Graduate School from the University of Potsdam for his permanent support and fruitful discussions. The authors also thank Ines Hebestadt for advice in the model simulations and acknowledge the helpful advices of two anonymous reviewers, who improved and clarified the manuscript.

\section{References}

[1] G.-S. Chen, Z. Liu, S. C. Clemens, W. L. Prell, and X. Liu, "Modeling the time-dependent response of the Asian summer monsoon to obliquity forcing in a coupled GCM: a PHASEMAP sensitivity experiment," Climate Dynamics, 2010.

[2] A. Dallmeyer, M. Claussen, and J. Otto, "Contribution of oceanic and vegetation feedbacks to Holocene climate change in Central and Eastern Asia," Climate of the Past Discussions, vol. 5, no. 5, pp. 2351-2389, 2009.

[3] N.-C. Lau and J. J. Ploshay, "Simulation of synoptic- and subsynoptic-scale phenomena associated with the East Asian summer monsoon using a high-resolution GCM," Monthly Weather Review, vol. 137, no. 1, pp. 137-160, 2009.

[4] C. L. Castro, R. A. Pielke Sr., and G. Leoncini, "Dynamical downscaling: assessment of value retained and added using the Regional Atmopsheric Modeling System (RAMS)," Journal of Geophysical Research D, vol. 110, no. 5, pp. 1-21, 2005.

[5] C. L. Castro, R. A. Pielke Sr., and J. O. Adegoke, "Investigation of the summer climate of the contiguous United States and 
Mexico using the Regional Atmospheric Modeling System (RAMS). Part I: model climatology (1950-2002)," Journal of Climate, vol. 20, no. 15, pp. 3844-3865, 2007.

[6] B. Bhaskaran, R. G. Jones, J. M. Murphy, and M. Noguer, "Simulations of the Indian summer monsoon using a nested regional climate model: domain size experiments," Climate Dynamics, vol. 12, no. 9, pp. 573-587, 1996.

[7] X. Cui, B. Langmann, and H.-F. Graf, "Summer monsoonal rainfall simulation on theT ibetan Plateau with a regional climate model using a one-way double-nesting system," Scientific Online Letters on the Atmosphere, vol. 3, pp. 49-52, 2007.

[8] A. Dobler and B. Ahrens, "Analysis of the Indian summer monsoon system in the regional climate model COSMOCLM," Journal of Geophysical Research D, vol. 115, no. 16, Article ID D16101, 2010.

[9] C. Fu, S. Wang, Z. Xiong et al., "Regional climate model intercomparison project for Asia," Bulletin of the American Meteorological Society, vol. 86, no. 2, pp. 257-266, 2005.

[10] Y. Ji and A. D. Vernekar, "Simulation of the Asian summer monsoons of 1987 and 1988 with a regional model nested in a global GCM," Journal of Climate, vol. 10, no. 8, pp. 1965-1979, 1997.

[11] J. V. Ratnam, F. Giorgi, A. Kaginalkar, and S. Cozzini, "Simulation of the Indian monsoon using the RegCM3-ROMS regional coupled model," Climate Dynamics, vol. 33, no. 1, pp. 119-139, 2008.

[12] T. Sato, "Influences of subtropical jet and Tibetan Plateau on precipitation pattern in Asia: insights from regional climate modeling," Quaternary International, vol. 194, no. 1-2, pp. 148-158, 2009.

[13] R. Schiemann, D. Lüthi, P. L. Vidale, and C. Schär, "The precipitation climate of Central Asia-intercomparison of observational and numerical data sources in a remote semiarid region," International Journal of Climatology, vol. 28, no. 3, pp. 295-314, 2008.

[14] J. H. Christensen and O. B. Christensen, "A summary of the PRUDENCE model projections of changes in European climate by the end of this century," Climatic Change, vol. 81, no. 1, pp. 7-30, 2007.

[15] R. Dankers, L. Feyen, and O. B. Christensen, "On the benefit of high-resolution climate simulations in impact studies of hydrological extremes," Hydrology and Earth System Sciences Discussions, vol. 6, pp. 2573-2597, 2009.

[16] A. Rinke and K. Dethloff, "Simulated circum-Arctic climate changes by the end of the 21st century," Global and Planetary Change, vol. 62, no. 1-2, pp. 173-186, 2008.

[17] H. Matthes, A. Rinke, and K. Dethloff, "Variability of extreme temperature in the Arctic-observation and RCM," Open Atmospheric Sciences Journal, vol. 4, pp. 126-136, 2010.

[18] A. Rinke, H. Matthes, and K. Dethloff, "Regional characteristics of Arctic temperature variability: comparison of observations with regional climate simulations," Climate Research, vol. 41, no. 3, pp. 177-192, 2010.

[19] Y. Xin, A. Rinke, L. Bian, K. Dethloff, C. Xiao, and M. Mielke, "Climate and forecast mode simulations for antarctica: implications for temperature and wind," Advances in Atmospheric Sciences, vol. 27, no. 6, pp. 1453-1472, 2010.

[20] K. Dethloff, K. Glushak, A. Rinke, and D. Handorf, "Antarctic 20th century accumulation changes based on regional climate model simulations," Advances in Meteorology, vol. 2010, Article ID 327172, 14 pages, 2010.
[21] J. H. Christensen, O. B. Christensen, P. Lopez, E. van Meijgaard, and M. Botzet, "The HIRHAM4 regional atmospheric climate model,” DMI Scientific Report 96-4, Danish Meteorological Institute, Kopenhagen, Denmark, 1996.

[22] K. Dethloff, A. Rinke, R. Lehmann, J. H. Christensen, M. Botzet, and B. Machenhauer, "Regional climate model of the Arctic atmosphere," Journal of Geophysical Research D, vol. 101, no. 18, pp. 23401-23422, 1996.

[23] A. Rinke, K. Dethloff, J. H. Christensen, M. Botzet, and B. Machenhauer, "Simulation and validation of Arctic radiation and clouds in a regional climate model," Journal of Geophysical Research D, vol. 102, no. 25, pp. 29833-29847, 1997.

[24] B. Machenhauer, "The HIRLAM final report," HIRLAM Technical Report 5, Danish Meteorological Institute, Kopenhagen, Denmark, 1988.

[25] E. Roeckner, K. Arpe, L. Bengtsson et al., "The atmospheric general circulation model ECHAM-4: model description and simulation of present-day climate," MPI Report 218, MaxPlanck-Institute for Meteorology, Hamburg, Germany, 1996.

[26] H. C. Davies, "A lateral boundary formulation for multilevel prediction models," Quarterly Journal of the Royal Meteorological Society, vol. 102, pp. 405-418, 1976.

[27] S. M. Uppala, P. W. Kållberg, A. J. Simmons et al., "The ERA40 re-analysis," Quarterly Journal of the Royal Meteorological Society, vol. 131, no. 612, pp. 2961-3012, 2005.

[28] U. Schneider, T. Fuchs, A. Meyer-Christoffer, and B. Rudolf, "Global precipitation analysis products of the GPCC," Tech. Rep., German Weather Service, Offenbach, Germany, 2008.

[29] M. Rajeevan, J. Bhate, J. D. Kale, and B. Lal, "High resolution daily gridded rainfall data for the Indian region: analysis of break and active monsoon spells," Current Science, vol. 91, no. 3, pp. 296-306, 2006.

[30] P. D. Clift and R. A. Plumb, The Asian Monsoon: Causes, History and Effects, Cambridge University Press, Cambridge, UK, 2008.

[31] J. Lighthill and R. P. Pearce, Monsoon Dynamics, Cambridge University Press, Cambridge, UK, 2009.

[32] B. Wang et al., The Asian Monsoon, Springer, Berlin, Germany, 2006.

[33] D. Zhang, X. Gao, L. Ouyang, and W. Dong, "Simulation of present climate over East Asia by a regional climate model," Journal of Tropical Meteorology, vol. 14, no. 1, pp. 19-23, 2008.

[34] X. Gao, Y. Xu, Z. Zhao, J. S. Pal, and F. Giorgi, "On the role of resolution and topography in the simulation of East Asia precipitation," Theoretical and Applied Climatology, vol. 86, no. 1-4, pp. 173-185, 2006.

[35] B. N. Goswami and P. K. Xavier, "ENSO control on the south Asian monsoon through the length of the rainy season," Geophysical Research Letters, vol. 32, no. 18, Article ID L18717, 4 pages, 2005.

[36] J. D. Farrara and J.-Y. Yu, "Interannual variations in the Southwest U.S. Monsoon and sea surface temperature anomalies: a general circulation model study," Journal of Climate, vol. 16, no. 11, pp. 1703-1720, 2003.

[37] S. K. Dash, M. S. Shekhar, and G. P. Singh, "Simulation of Indian summer monsoon circulation and rainfall using RegCM3," Theoretical and Applied Climatology, vol. 86, no. 14, pp. 161-172, 2006. 

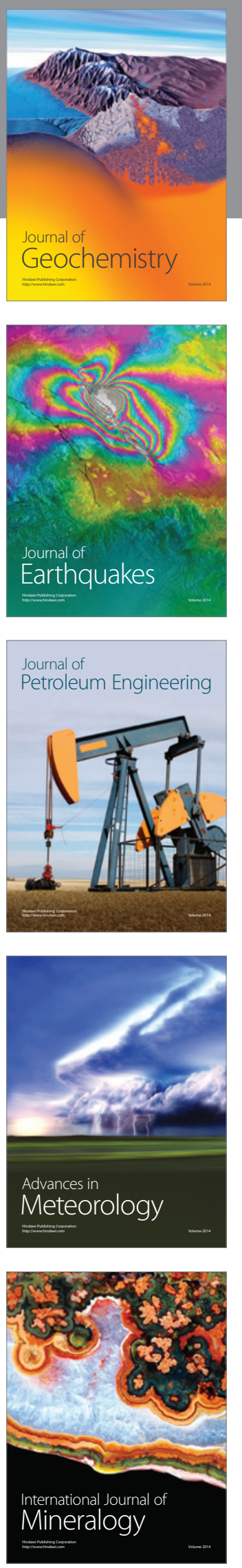
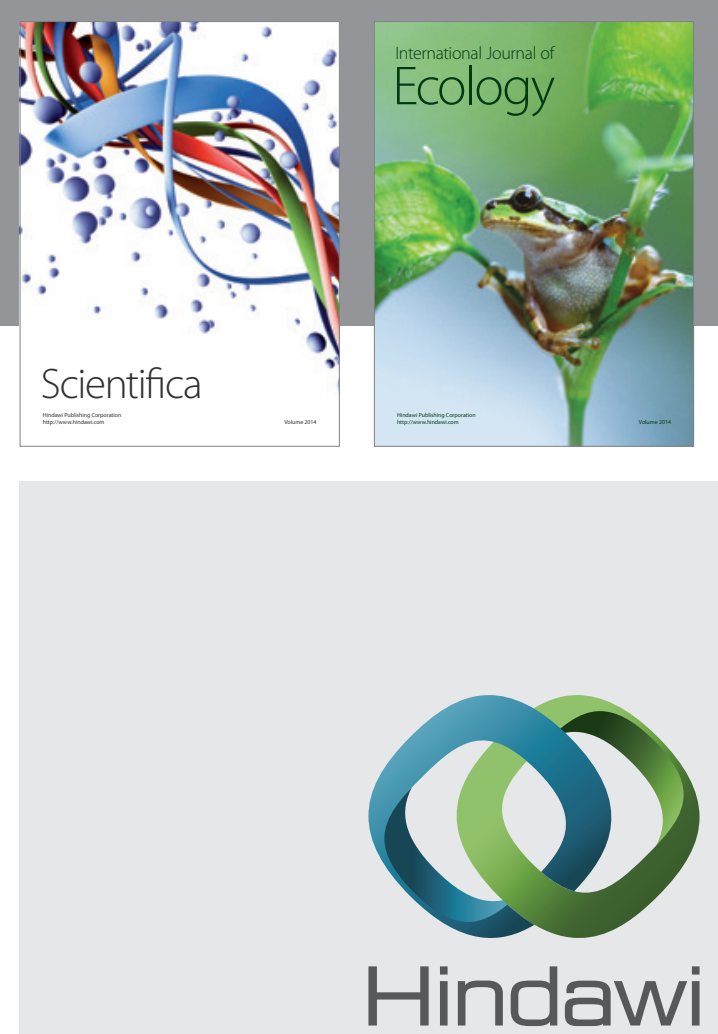

Submit your manuscripts at http://www.hindawi.com
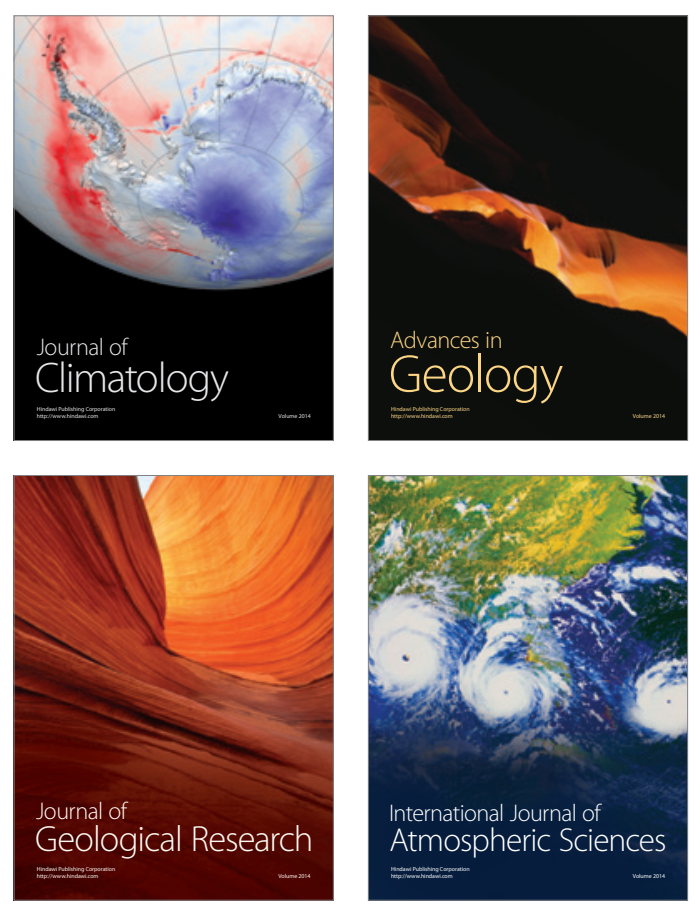
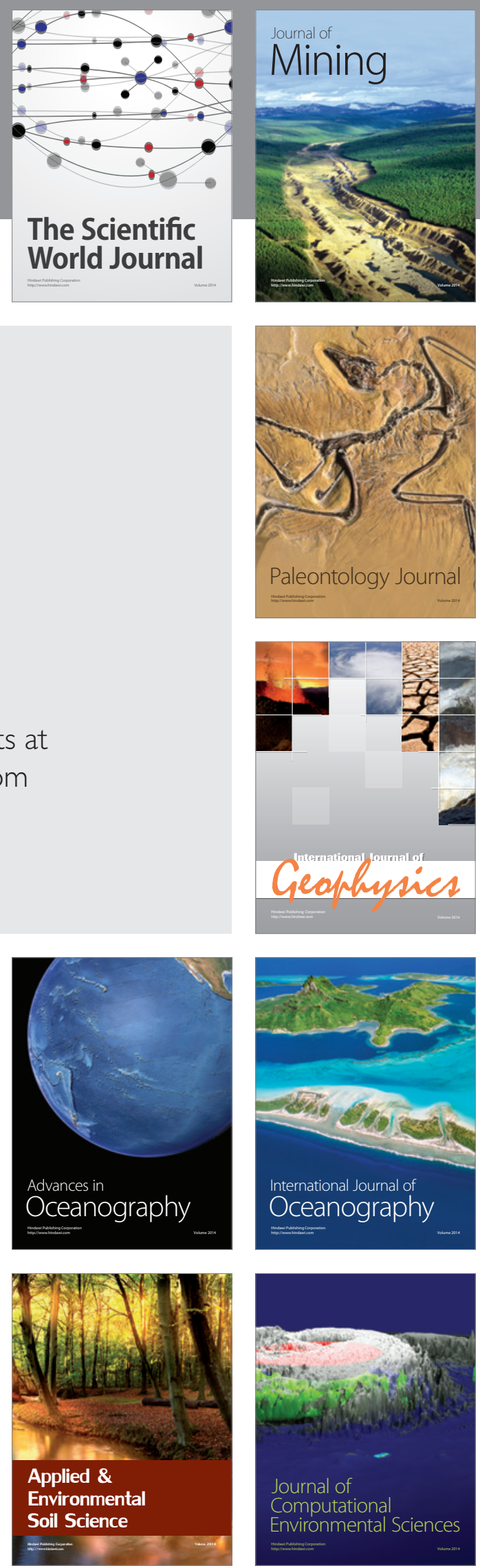